\title{
Effects of Ibotenate Hippocampal and Extrahippocampal Destruction on Delayed-Match and -Nonmatch-to-Sample Behavior in Rats
}

\author{
Robert E. Hampson, ${ }^{1}$ Leonard E. Jarrard, ${ }^{2}$ and Sam A. Deadwyler ${ }^{1}$ \\ ${ }^{1}$ Department of Physiology and Pharmacology, Wake Forest University School of Medicine, Winston-Salem, North \\ Carolina, 27157-1083 and 'Department of Psychology, Washington and Lee University, Lexington, Virginia 24450
}

The effects of ibotenate lesions of the hippocampus (HIPP) or hippocampus plus collateral damage to extrahippocampal structures (HCX) were investigated in rats trained to criterion on spatial versions of either a delayed-match (DMS) or delayednonmatch-to-sample (DNMS) task. After recovery from surgery, animals were retrained at "0" sec delays, then assessed at 0-30 $\mathrm{sec}$ delays for $15 \mathrm{~d}$, retrained again at $0 \mathrm{sec}$ delays, and retested for another $25 \mathrm{~d}$ on $0-30 \mathrm{sec}$ delays. Pretrained HIPPlesioned animals showed marked delay-dependent deficits in both tasks that never recovered. Detailed examination of within- and between-trial performance factors, including changes in response preferences, length of previous trial delay, and sequential dependencies, revealed important factors operating in lesioned animals that were either absent or insignificant

The effects of hippocampal lesions on delayed-match (DMS) and delayed-nonmatch-to-sample (DNMS) performance have historically provided evidence of selective influences on short- versus long-term memory processes (Correll and Scoville, 1965; Olton and Feustle, 1981; Rawlins, 1985; Parkinson et al., 1988; Raffaele and Olton, 1988; Zola-Morgan et al., 1993; Shaw and Aggleton, 1995). In recent years the validity of this assumption has been repeatedly tested with respect to the species of animal (Aggleton and Mishkin, 1985; Rothblat and Kromer, 1991; Gaffan and Murray, 1992; Rawlins et al., 1993), type of delay task used, (Parkinson et al., 1988; Dunnett, 1989; Rothblat and Kromer, 1991; Rawlins et al., 1993; Steele and Rawlins, 1993; Cassaday and Rawlins, 1995), number of choices available (Angeli et al., 1993; Gutnikov et al., 1994), type and extent of the lesion (Aggleton and Mishkin, 1985; Aggleton et al., 1989; Jarrard, 1989, 1993; Coffey et al., 1990; Rawlins et al., 1993), nature of stimuli used (Angeli et al., 1993; Yee and Rawlins, 1994; Cassaday and Rawlins, 1995), and methods of scoring the data (Ringo, 1991; Steele and Rawlins, 1993).

Several of these issues can be reduced to four important aspects of DMS and DNMS behavior that have yet to be unequivocally determined in animals that have damage to the hippocampus and related structures. The first is whether the deficit in DMS and

Received Sept. 25, 1998; revised Nov. 30, 1998; accepted Dec. 2, 1998.

This research was supported by National Institute on Drug Abuse Grants DA03502 and DA00119 to S.A.D. and DA08549 to R.E.H. We thank Doug Byrd, Joanne Konstantopoulos, and Terry Bunn for technical assistance.

Correspondence should be addressed to Dr. Robert Hampson, Department of Physiology and Pharmacology, Wake Forest University School of Medicine, Medical Center Boulevard, Winston-Salem, NC 27157-1083.

Copyright (C) 1999 Society for Neuroscience $\quad 0270-6474 / 99 / 191492-16 \$ 05.00 / 0$ before the lesion. Pretrained HCX-lesioned animals showed deficits similar to those of HIPP animals, with the noticeable exception of a strong "recency" influence of the previous trial. Another group of HIPP- and HCX-lesioned animals trained on the tasks after the lesion showed reduced impairments of the type described above, suggesting that extrahippocampal structures trained after the lesion can assume the role of the hippocampus to some degree. The findings indicate that both the type of lesion and the previous history of the animal determine the postlesion DMS and DNMS performance of animals suffering damage to the hippocampus and/or related structures.

Key words: ibotenate lesion; hippocampus; subiculum; entorhinal cortex; delay tasks; memory; training

DNMS performance reported with lesions of the hippocampus is truly delay-dependent, i.e., increased impairment (relative to control levels) as length of delay interval is increased (Ringo, 1991; Alvarez-Royo et al., 1992; Zola-Morgan et al., 1993). The second issue is whether animals with selective hippocampal lesions actually perform the task in the same manner that they did before the lesion. In such instances plotting the data in the same manner for pre- versus postlesion conditions can obscure qualitative differences in performance and possibly mask more severe deficits in the lesioned animal (Dunnett, 1989). The third issue regards the nature and extent of the damage and whether the deficits that are reported are caused by isolated involvement of the hippocampus and/or damage to adjacent structures and fibers of passage (Jarrard, 1993; Murray and Mishkin, 1998). Finally, are the same deficits observed in animals that are pretrained on the task before the lesion versus those trained after the lesion (Irle and Markowitsch, 1990; Ridley et al., 1996; Maren et al., 1997)?

In the following report we demonstrate that selective lesions of the hippocampus that spare other structures and preserve fibers of passage severely disrupt performance on operant-spatial DMS and DNMS tasks. The lesion-produced disruption was specific to (1) hippocampal versus hippocampal plus collateral retrohippocampal involvement, (2) the length of delay interval, (3) factors operating within versus between trials, and (4) whether the animal was pretrained on the task at the time of the lesion. The data support the conclusion that the hippocampus is critical for successful performance in this version of the DMS and DNMS task as suggested in previous electrophysiological investigations (Deadwyler et al., 1996; Hampson et al., 1998a,b). 

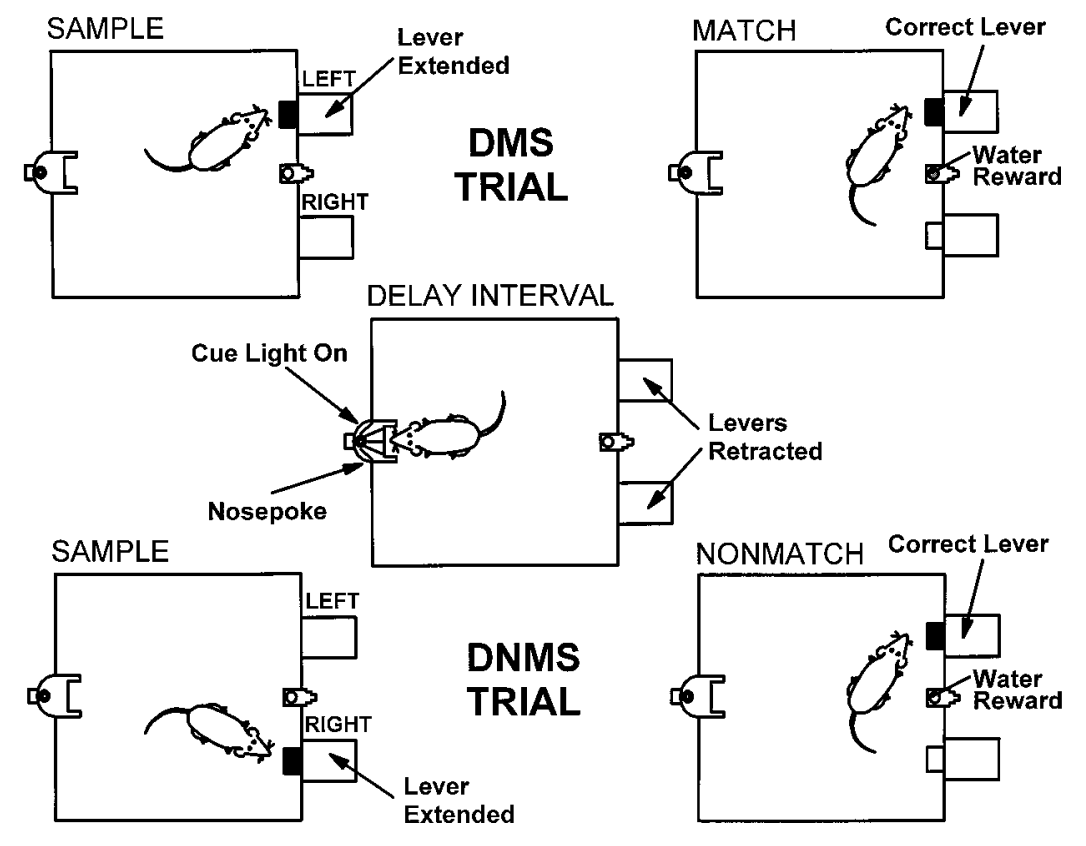

Figure 1. Diagram showing apparatus and contingencies for DMS (top) and DNMS (bottom) tasks. The middle box (Delay Interval) shows that the delay is the same for both types of tasks and consists of requisite nosepokes during the duration of the delay period. Typical behavior is for the animal to nosepoke through the entire delay period of $0-30$ sec while the cue light is illuminated. Note that the $D M S$ type trial constitutes an error if the animal is performing the $D N M S$ task and vice versa. For the Sample phase of the task, the dark lever is the only one presented and to which the animal can respond. For the Match or Nonmatch phase of the task, the dark lever is the correct response to the two levers that are extended simultaneously into the chamber at the end of the delay interval.

\section{MATERIALS AND METHODS}

Subjects. Forty-one male Spraque Dawley rats ranging in age from 150 to $200 \mathrm{~d}$ at the initiation of training were used as subjects. The time of surgery and the time of training were interleaved over multiple stages in which different groups of animals (usually $6-10$ per group) were trained, lesioned, and tested over several months. All animals were trained to the same criteria before surgery, except in the case of the "naive" group that only received training on the task after surgery. Several subjects were eliminated in the early stages of the study as a consequence of adjustments to the ibotenate lesion protocol, age of the rat, and variations in quality of the toxin.

Apparatus. The apparatus was similar to that used in other studies from this laboratory (Hampson et al., 1993; Deadwyler et al., 1996). Briefly, all studies were conducted in $43 \mathrm{~cm} \times 43 \mathrm{~cm} \times 53 \mathrm{~cm}$ Plexiglas behavioraltesting chambers with manipulanda and other features described previously (Deadwyler et al., 1996). The entire apparatus was housed inside a commercial sound-attenuated cubicle (Industrial Acoustics, Bronx, NY). On one wall of the chamber, two retractable levers (Coulborn Instruments, Lehigh Valley, PA) were positioned $3.5 \mathrm{~cm}$ above the floor and separated by $14.0 \mathrm{~cm}$ (center to center). A water dispenser trough was positioned midway between the levers. A nosepoke device, consisting of an infrared photodetector and light-emitting diode spanning a $2.5 \mathrm{~cm} \times$ $1 \mathrm{~cm} \times 1 \mathrm{~cm}$ opening in an aluminum housing, was mounted $4.0 \mathrm{~cm}$ above the chamber floor on the wall opposite the levers with a cue light $(6 \mathrm{~V} ; 10$ W) positioned immediately above it. A speaker mounted on one wall provided a constant $85 \mathrm{db}$ "white noise" background. Two $12 \mathrm{~V}, 25 \mathrm{~W}$ incandescent lamps (house lights) were mounted on the top of the chamber. Video monitoring of the animal was provided by a Sanyo CCD black-and-white video camera mounted above the chamber. The apparatus was controlled by a personal computer that collected all behavioral data, which were subsequently stored on hard drives and then archived to optical disks.

Behavioral training procedure. Animals were water-deprived and allowed free access to food for maintenance at $85 \%$ of their weight throughout the duration of DMS and DNMS training (Hampson et al., 1993). Periodically animals were given water and food ad libitum, and a new weight was calculated to allow for normal body growth. Before each behavioral session, all animals were typically water-deprived for 20-22 hr. The DMS and DNMS tasks were similar to those described previously by Hampson et al. (1993) and Deadwyler et al. (1996), respectively. Delay interval responding was performed via a nosepoke device on the wall opposite the levers so that animals could not use orienting strategies to code lever position during the delay intervals (Chudasama and Muir, 1997).

Pretraining in both tasks was as described in Hampson et al. (1993). Briefly, the task consisted of three main phases: sample, delay, and match or nonmatch. At the initiation of a trial, either the left or right lever was extended, and the animal was allowed to respond on the extended lever (sample response) while the other lever remained retracted (Fig. 1, sample). The sample lever was then retracted, and the delay phase was initiated (Fig. 1, delay interval) and varied randomly on any given trial from 0 to $30 \mathrm{sec}$. During the delay the animal was required to nosepoke in the photocell device, mounted on the opposite wall, in the presence of the adjacent illuminated cue light; nosepokes shut off the light on a variable interval schedule the average of once every $16 \mathrm{sec}$ in conjunction with the delay contingency. At the termination of the delay interval, if a nosepoke occurred during the delay, the cue light was turned off, and both levers were extended into the chamber, signaling onset of the match or nonmatch phase of the task (Fig. 1). The animal was then required to press either the same [match (DMS)] or opposite [nonmatch (DNMS)] lever compared with the previous sample lever response (Fig. 1, correct lever). If successful, the match or nonmatch response produced a distinct "click" of the solenoid valve that delivered a drop of water to the trough located between the two levers (Fig. 1, water reward). The levers were then retracted for a $10 \mathrm{sec}$ intertrial interval (ITI). Note that Figure 1 also illustrates that performance of a DMS-type response pattern would constitute an error for the DNMS task, and performance of a DNMS pattern results in an error for the DMS task. On error trials, inappropriate responding was followed by an immediate $5 \mathrm{sec}$ time-out period in which all lights were turned off and the levers were retracted, leaving the chamber completely dark for $5 \mathrm{sec}$. The chamber lights were then turned back on, and $5 \mathrm{sec}(10 \mathrm{sec}$ ITI) later the next trial was initiated. A new trial always commenced with the extension of one of the two levers (right or left) in the sample phase after a $10 \mathrm{sec}$ ITI. Daily training and testing sessions typically consisted of 100-150 trials.

Animals were trained to a criterion of $>90 \%$ correct responses during sessions of 100 trials with "0" sec delays that essentially consisted of performing the required response sequence [i.e., sample, nosepoke, and match or nonmatch (Fig. 1)] without interruption by a perceptible delay interval between the sample and match or nonmatch responses. They were then trained on trials with delays that varied randomly between 0 and $15 \mathrm{sec}(5 \mathrm{~d})$ and then 0 and $30 \mathrm{sec}$ until a final criterion of $>85 \%$ correct responding on trials with delays of $\leq 5 \mathrm{sec}$ was met by all animals (i.e., no performance criterion was set for trials with delays of $>5 \mathrm{sec}$ ). Before the lesion, equal numbers of animals were trained to the same criteria on either task, which required approximately the same number of daily sessions $(\mathrm{DMS}=12.1 \pm 0.9$ sessions; DNMS $=17.3 \pm 1.1$ sessions; mean \pm SEM). A second group of animals received either DMS $(n=4)$ or DNMS $(n=4)$ training after the lesion (naive-lesioned animals). A third group $(n=4)$ received training on just lever responding without the discrimination or delay components before the lesion.

Lesions. The surgical procedures used to administer ibotenate lesions of the hippocampus were similar to those described elsewhere (Jarrard, 1989). Specifically, the animals were anesthetized with a mixture of 
chloral hydrate and sodium pentobarbital and placed in a Kopf stereotaxic apparatus; then an incision was made in the scalp, and the bone overlying the hippocampus was removed. Injections of ibotenic acid (IBO) were made with a $5 \mu$ l Hamilton syringe mounted on the stereotaxic frame and held with a Kopf microinjector (Model 5000). A glass micropipette was glued onto the end of the needle of the syringe to minimize damage to overlying neocortex. The IBO was dissolved in PBS, $\mathrm{pH} 7.4$, at a concentration of $10 \mathrm{mg} / \mathrm{ml}$. Injections of $0.1 \mu \mathrm{l}(0.05 \mu \mathrm{l}$ at several sites) were made over $\sim 30 \mathrm{sec}$ at each of 26 sites (for stereotaxic coordinates, see Jarrard, 1989). The pipette was left in place an additional $30 \mathrm{sec}$ to prevent spread up the pipette track.

Ibotenate lesions were administered to 24 animals that survived surgery and testing. Animals were classified with respect to the extent and completeness of hippocampal damage into two main classes, (1) complete hippocampal removal (HIPP) or (2) hippocampal removal plus collateral damage to retrohippocampal structures (HCX). After evaluation of the lesion, the above groups were further subdivided by type of lesion and task for final analyses.

Postlesion testing. Testing was commenced 1-2 weeks after surgery after the animals had regained their prelesion body weight levels. For animals pretrained to criterion on the DMS and DNMS tasks, initial postlesion testing consisted of 5-7 d of training on the task with a $0 \mathrm{sec}$ delay period. All animals reached a $100 \%$ criterion performance within $5-7 \mathrm{~d}$ on the 0 delay version of the task. They were then directly exposed to daily sessions consisting of trials with $0-30 \mathrm{sec}$ delays for the same number of successive days that they were trained before the lesion (see above). After this, another 7-9 d of training with only 0 delay trials was interjected before animals were tested again under the $0-30$ sec condition for an extended period $(24 \mathrm{~d})$ to determine whether they could regain prelesion performance levels. All daily sessions consisted of 100-120 trials. Animals lesioned before training (naive-lesioned group) were trained in the same manner as were the pretrained animals (see Behavioral Training Procedure), and the number of days to reach criterion performance was noted for each animal.

Behavioral data analyses. Assessment of behavioral data consisted of several different analyses designed to elucidate the deficits produced by removing the hippocampus. The two primary measures used to test preto postlesion differences were mean percent correct performance over the entire session for each type of trial (i.e., left or right) and mean percent correct performance at each delay interval, assessed in $5.0 \mathrm{sec}$ intervals. Additional measures included time of execution of the trial, influence of previous trial delay, and the number of daily sessions to recover criterion performance. Multifactor ANOVAs were used for most tests, and adjusted pairwise linear comparisons were used for individual comparisons. The consistency in the data suggests that data from animals within the same groups tested at different times did not influence the results.

Histology. After completion of behavioral testing, all animals were administered a lethal dose of pentobarbital and perfused with physiological saline followed by formalin. The brains were removed from the skull, embedded in egg yoke, and cut into $40 \mu \mathrm{m}$ coronal sections on a microtome. A cresyl violet stain was used to determine cell loss attributable to the lesion, and selected sections were stained with the FinkHeimer silver staining procedure (Fink and Heimer, 1967) to identify degenerating axons and argyrophylic cells. The extent of hippocampal cell loss together with any encroachment into adjacent structures was determined by visual inspection (Jarrard, 1991). In addition, preservation of fibers of passage and other noncellular structural changes were evaluated (Jarrard, 1989).

\section{RESULTS}

\section{Histology}

The nature and extent of the brain damage resulting from ibotenate lesions of the hippocampus can be seen in Figure 2. The photomicrographs are of cell-stained sections taken from three rostrocaudal levels through the hippocampus. Evaluation of the resulting damage indicated that in some animals the damage was limited to the hippocampus (CA1-CA3 pyramidal cells, dentate granule cells, and interneurons), but there were some that had, in addition to the removal of the hippocampus, bilateral damage that included adjacent retrohippocampal areas (subiculum, preand/or parasubiculum, and/or entorhinal cortex). Thus, for pur- poses of behavioral analysis, animals were subdivided into two groups: those that had the hippocampus removed selectively (HIPP group, $n=12$ ) and a group that received collateral damage to retrohippocampal areas in addition to complete removal of the hippocampus (HCX group, $n=6$ ). Representative lesions from the HIPP and HCX groups and an intact control brain are shown in Figure 2.

Histological evaluation of the resulting damage indicated that most of the animals had essentially complete removal of the pyramidal (CA1-CA3) and dentate granule cells at all rostralcaudal levels of the hippocampus (see Fig. 2). Although there were several animals in this group that had some sparing of pyramidal cells and/or dentate granule cells, these cells were few in number and were confined mostly to the ventral hippocampus. Furthermore, there was an absence of obvious damage to the subiculum and adjacent retrohippocampal areas (HIPP-lesioned animals). As can be seen in Figure 2, there was considerable atrophy of the hippocampus; however, the axons normally found in the fimbria and fornix could be seen clearly, forming a tight bundle of fibers coursing along the dorsolateral edge of the thalamus. It was shown in previous research that these axons could transport horseradish peroxidase, and these axons are thus assumed to be still functional after this kind of lesion (Jarrard, 1989). The damage described above is essentially similar to that found in other experiments in which the same surgical procedure was used (Jarrard and Davidson, 1994; Jarrard, 1995).

In addition to loss of cells that form the hippocampus, animals in the HCX group had damage that was bilateral and extended in a caudal direction to include neurons in several adjacent retrohippocampal areas (subiculum, pre- and/or parasubiculum, and/or entorhinal cortex). Although the exact nature and extent of this additional damage did vary from animal to animal, the common feature was that the damage was more extensive than in HIPP rats and included areas that are afferent and/or efferent to the hippocampus.

\section{Effects of hippocampal removal on DMS or DNMS performance}

For behavioral analysis, animals in the HIPP and HCX groups were further divided into subgroups based on pretraining or no pretraining and type of task. Thus, two major groups consisted of animals with HIPP lesions pretrained to criterion on the DNMS or DMS task and retested after recovery from surgery. Two other HIPP-lesioned animals $(n=2)$ did not receive pretraining on either the DNMS or DMS tasks. These animals were naive when training commenced after surgery (see below).

Two groups of six rats each were trained on the DMS or DNMS tasks before surgery and had lesions limited to the hippocampus (HIPP lesion). Data were analyzed with respect to three main factors that characterized the lesion deficits including (1) alteration in the delay dependence of DMS or DNMS performance (Hampson et al., 1998a), (2) qualitative differences in the degree of proactive influence from the previous trial (Deadwyler et al., 1996; Hampson and Deadwyler, 1996b), and (3) presence of a response bias, or preference, for a particular trial type (Deadwyler et al., 1996).

\section{Effects on DMS performance}

Figure $3 A$ shows overall pre- versus postlesion mean performance for all pretrained HIPP-lesioned animals in the DMS (0-30 sec delay) task. Mean overall DMS performance decreased after the lesion from 81 to $73 \%\left[F_{(2,327)}=48.21 ; p<0.001\right]$. The decre- 


\section{CONTROL}
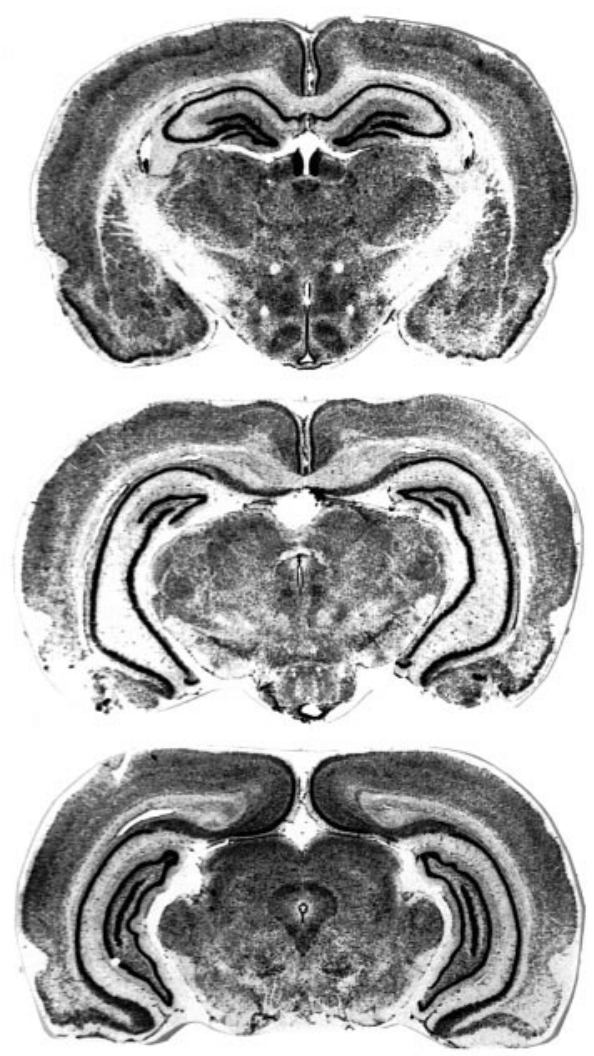

HIPPOCAMPUS

HCX
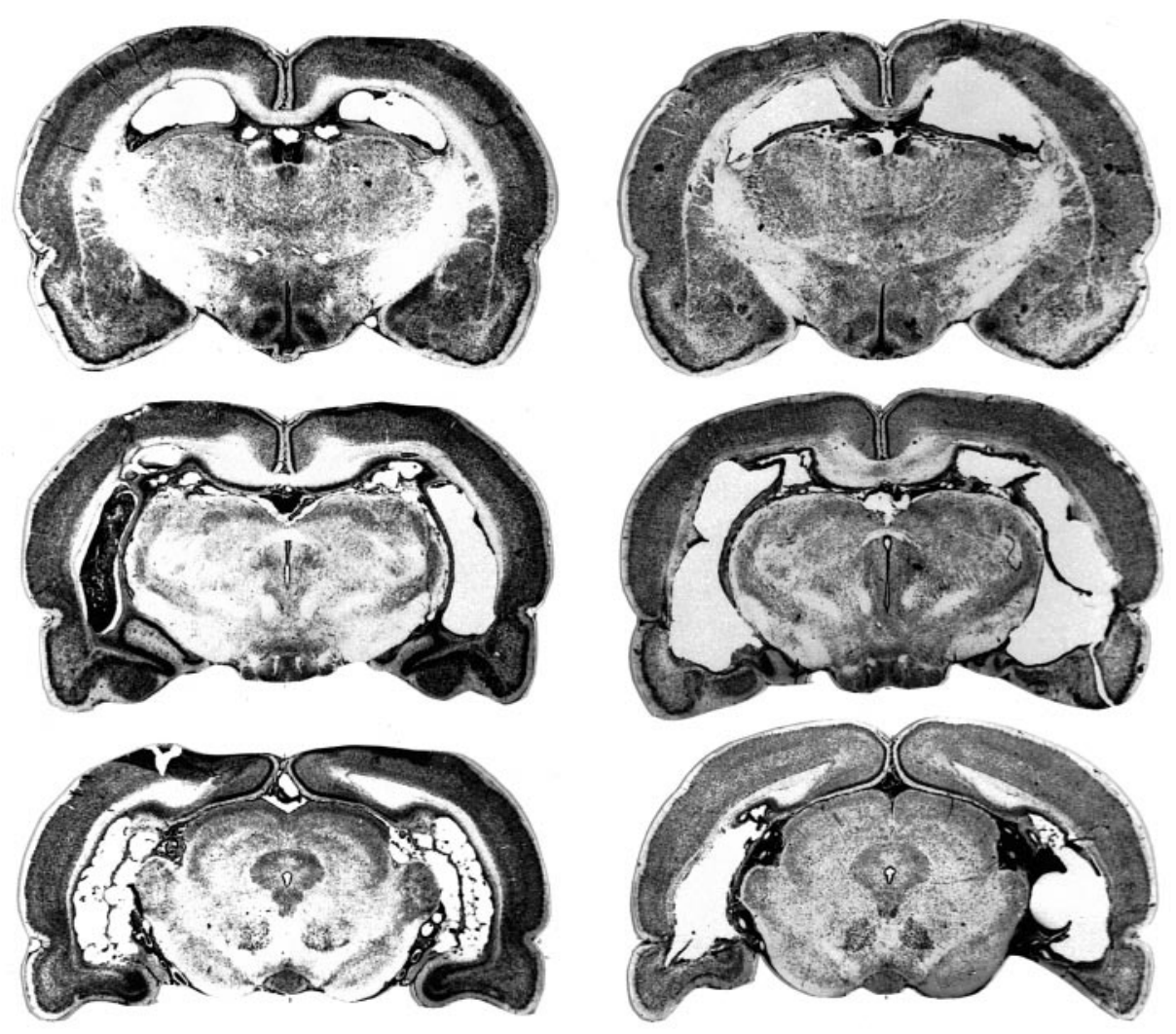

Figure 2. Representative ibotenate lesions for hippocampal (Hippocampus or HIPP, center) and retrohippocampal (HCX, right) groups, compared with the brain from an intact animal (Control, left). The spaces devoid of hippocampal tissue are filled in some cases with the embedding material so that region of the section appears darker than regions where there is no material adhering to the section. Further description is in text.

ment was delay dependent, larger at longer than at shorter delays $\left[F_{(1,1263)}=8.12 ; p<0.01\right]$, and was consistent across animals (see Fig. $3 A$, inset) as well as trials. There were no significant differences in pre- versus postlesion performance on trials with $0 \mathrm{sec}$ delay (Fig. 3A).

Because it was known that DMS and DNMS task performance in intact animals was influenced by different trial sequences (Hampson et al., 1995; Hampson and Deadwyler, 1996b), analyses of individual trial-type performance were performed on preand postlesion data. Figure $4 A$ shows pre- and postlesion performance sorted by "preferred" versus "nonpreferred" trials, a measure that accounted for differential responding on each of the two trial types [left (L) or right (R)] in the DMS task. Preference was defined by the position of the sample lever ( $\mathrm{L}$ or R) at the start of the trial. Hence a preferred (P)-type trial was defined as that with the higher average success rate during the session. The analysis revealed a modest $\left[F_{(8,881)}=2.75 ; p<0.01\right]$ difference $(15 \%)$ in intact animals with respect to performance on preferred (mean $=$ $88.7 \%$ ) versus nonpreferred (mean $=73.6 \%$ ) trials. A major difference in this measure was that before the lesion, trial preference was quite inconsistent across different sessions, as reflected in fluctuating mean differences from day to day (see multiple curve crossings in Fig. 4A, Prelesion). After surgery (Fig. $4, L)$, the trial preferences of HIPP-lesioned animals remained consistent from day to day over all postlesion test sessions (Fig. $4 A$ ). If sessions with only $0 \mathrm{sec}$ delay trials were administered
(Fig. 4A, days 1-5 Postlesion), preference was minimized. On sessions with $0-30 \mathrm{sec}$ trials, the mean separation in performance on preferred versus nonpreferred trials was markedly increased relative to pretraining levels [preferred trial mean $=83.9 \%$; nonpreferred trial mean $\left.=59.6 \% ; F_{(8,881)}=4.45 ; p<0.001\right]$.

Figure $4 B$ shows mean pre- and postlesion DMS performance of pretrained HIPP-lesioned animals as a function of short (1-10 $\mathrm{sec})$, intermediate (11-20 sec), and long (21-30 sec) delay trials. Postlesion mean performance on sessions with $0 \mathrm{sec}$ delays was clearly not impaired, and the ranking and the relative difficulty of the three delay categories remained the same as that in prelesion tests. There was, however, a significant reduction in pre- versus postlesion performance in all three delay categories $\left[F_{(8,821)}=\right.$ 4.18; $p<0.001]$ that never recovered, even over the extended (second 24 day) testing period (Fig. 4B).

\section{Effects on DNMS performance}

Figure $3 B$ shows the performance of the group of pretrained HIPP-lesioned animals $(n=6)$ on the DNMS task. The overall postlesion reduction in DNMS performance was from $79 \%$ (pre) to $71 \%$ (post) across all delay intervals. As with the DMS task, performance decreased significantly $\left[F_{(2,327)}=35.97 ; p<0.001\right]$ in a delay-dependent manner after the lesion, with longer delays producing more of a deficit relative to prelesion performance. Also as with the DMS task, the effect across animals was consistent (see Fig. 3B, inset) with the analysis across trials, while 
A.

\section{DMS Performance}

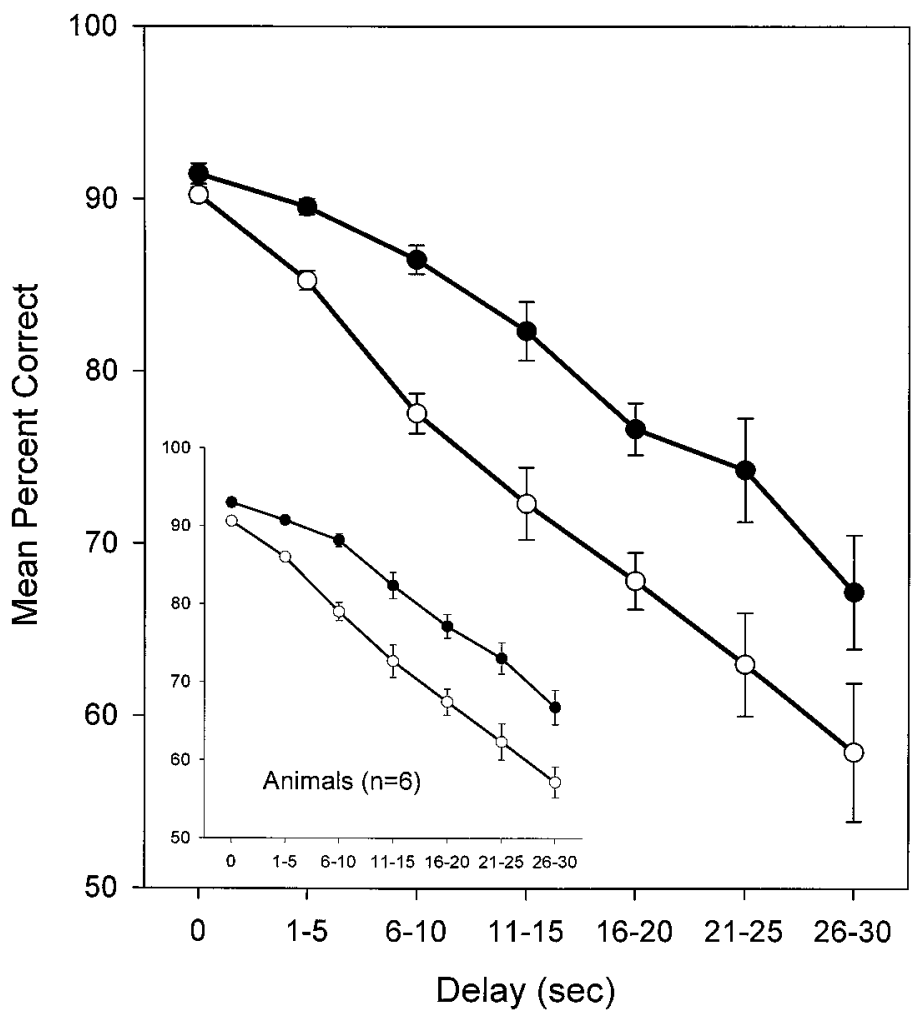

B.

DNMS Performance

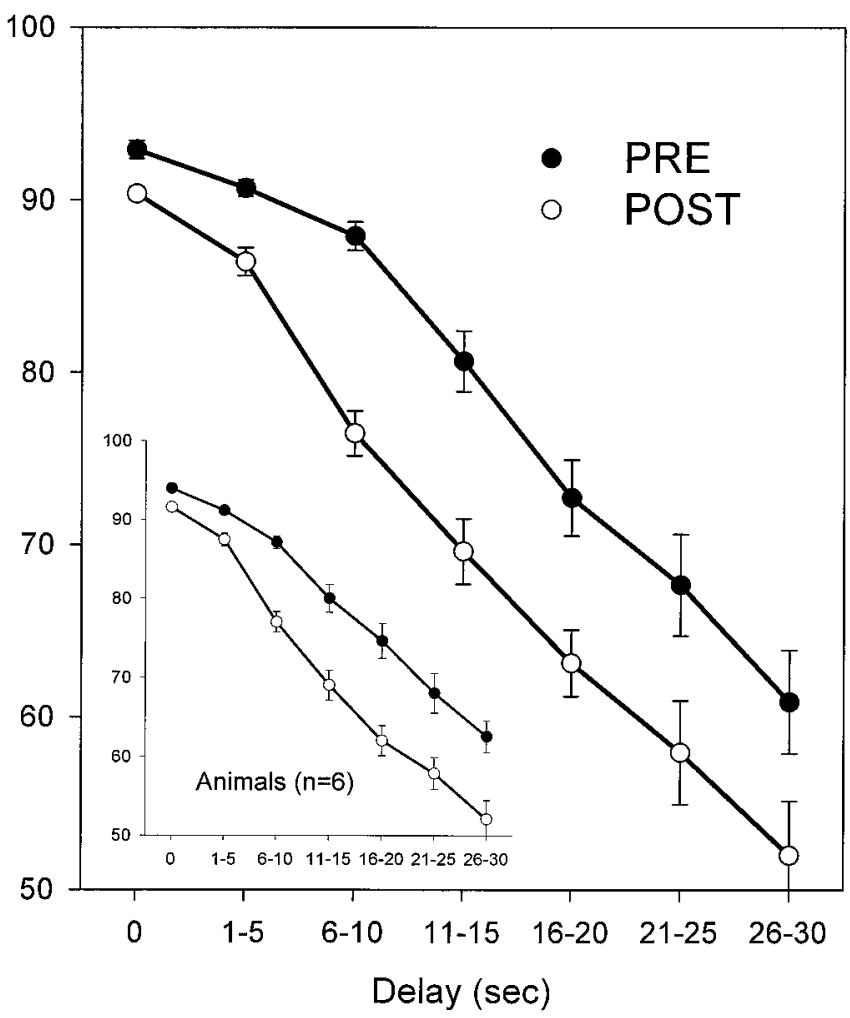

Figure 3. Comparison of pre- and postlesion performance of HIPP-lesioned animals in the $D M S$ and $D N M S$ tasks. $A, D M S$ trials were sorted by preand postlesion performance according to length of delay on individual trials and were grouped according to 5 sec intervals $(1-5,6-10,11-15,16-20$, 21-25, and 26-30). Trials with $0 \mathrm{sec}$ delays are plotted as a separate point to indicate performance levels with no apparent delay between sample and match or nonmatch phases of the task (see text). Prelesion $(n=11$ sessions) and postlesion $(n=11$ sessions) performance was averaged across trials, sessions, and animals $(n=6)$. Each symbol thus represents the mean $( \pm$ SEM) percent of correct trials performed within each delay across sessions. Prelesion performance was calculated from 0 to $30 \mathrm{sec}$ delay $D M S$ sessions immediately before surgery. Postlesion performance was calculated from the same number of 0-30 sec delay sessions immediately after surgery. Inset, The mean of each individual animal's performance at each delay is shown such that the variability reflects differences between animals in the group. $B, D N M S$ trials were sorted as in $A$ by pre- and postlesion performance according to length of delay on individual trials. Prelesion ( $n=15$ sessions) and postlesion $(n=15$ sessions) performance was averaged across trials, sessions, and animals for six animals that received ibotenate lesions confined to the hippocampus. Each symbol indicates the mean ( \pm SEM) percent of correct $D N M S$ trials performed within each delay across sessions. As in $A$, prelesion and postlesion DNMS performance was calculated for the same number of $0-30$ sec delay sessions immediately before and after the lesion surgery. Inset, The mean performance at each delay averaged across animals is shown.

postlesion performance on the 0 delay version of the task was unaffected (Fig. 3B). The analysis of performance on preferred $($ mean $=87.2 \%)$ versus nonpreferred $($ mean $=74.5 \%)$ trials (Fig. $5 A)$ also revealed a significant $\left[F_{(8,881)}=2.39 ; p<0.01\right]$ prelesion difference $(12 \%)$ that increased $(23 \%)$ after the lesion (preferred mean $=78.8 \%$; nonpreferred mean $=55.6 \%)$. As with the DMS task, the preferences of HIPP-lesioned animals were fixated and remained the same across all postlesion test sessions. The effect of the lesion at different delays was also similar to that of the pretrained HIPP-lesioned DMS group in that performance was significantly reduced (by $\sim 10 \%$ ) in each of the short, intermediate, and long delay categories in the first $\left[F_{(2,327)}=39.8 ; p<\right.$ $0.001]$ and second $\left[F_{(2,327)}=19.4 ; p<0.001\right]$ postlesion test periods (Fig. $5 B$ ). A comparison of pre- and postlesion performance between the DMS and DNMS groups revealed no significant differences $\left[F_{(8,881)}=0.29\right.$, NS $]$; however, there was the suggestion of a trend in postlesion improvement on 11-20 sec delay trials in the DNMS group that was not present in the DMS group (compare Figs. $4 B, 5 B$ ). Across all pretrained HIPPlesioned animals, irrespective of task, mean performance was considerably reduced at delays of $>5.0 \sec \left[F_{(8,1026)}=3.49 ; p<\right.$ $0.001]$ compared with prelesion levels. In addition, the difference in performance on preferred versus nonpreferred trials for both tasks was significantly magnified relative to prelesion levels [DMS, 24\%; DNMS, 24\%; $\left.F_{(8,881)}=4.51 ; p<0.001\right]$.

\section{Interactions with trial sequence \\ Prelesion influence}

Previous studies of DMS and DNMS performance in intact animals showed proactive influences from different trial sequences (Hampson and Deadwyler, 1996b; Hampson et al., 1998a). The performance of HIPP-lesioned animals was assessed using similar analyses to determine whether proactive influences differed after the lesion. Trials were grouped and sorted into categories depending on whether they were (1) preferred $(\mathrm{P})$ or nonpreferred $(\mathrm{N})$ and (2) preceded by a preferred or nonpreferred trial. This gave rise to four categories of trial doublets (P-P, N-N, N-P, and P-N; e.g., P-N, a nonpreferred current trial preceded by a preferred prior trial) for which performance could be plotted separately. 
A. Trial Type DMS

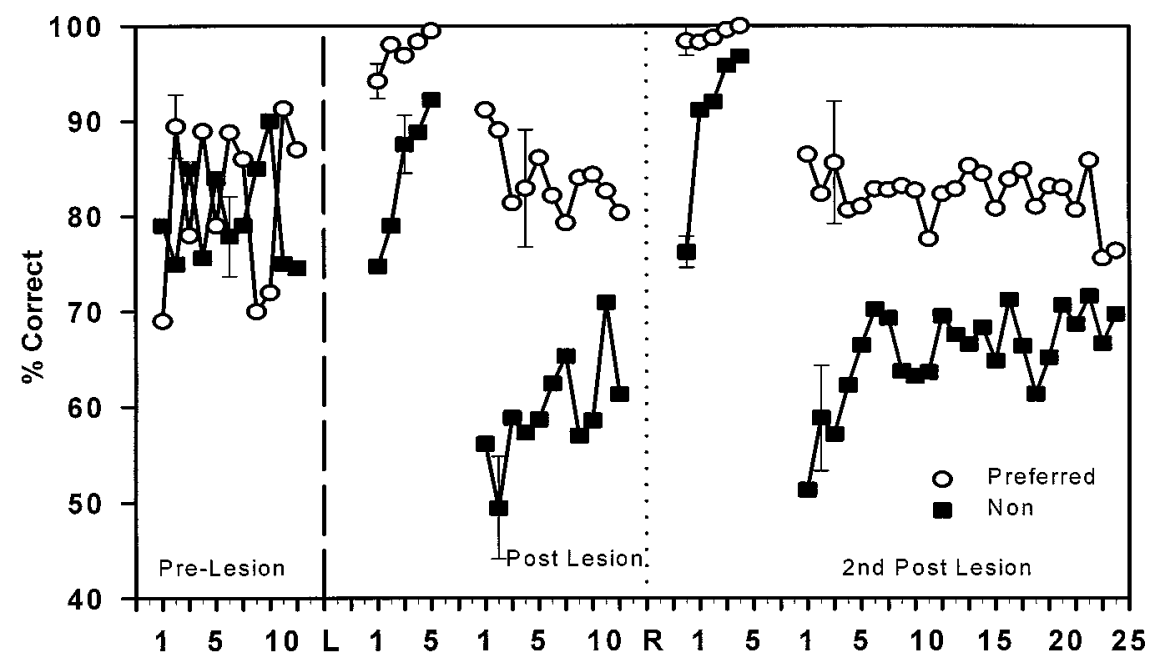

B. Delays DMS

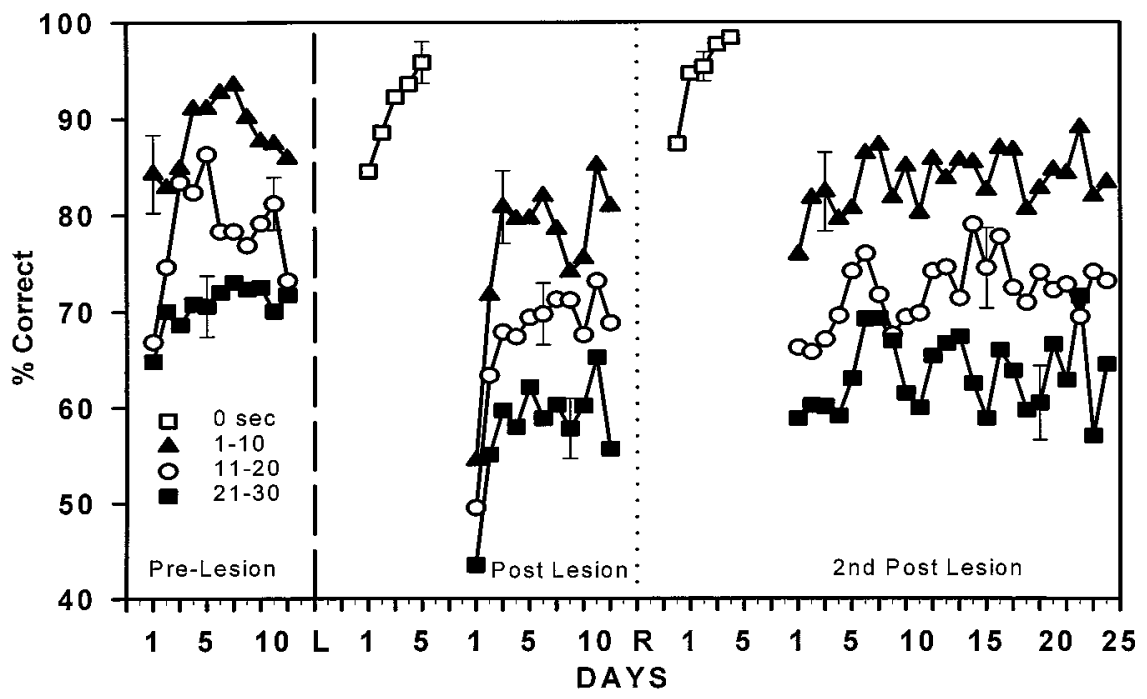

Figure 4. DMS performance in pretrained HIPPlesioned animals. $A$, Mean performance in the $D M S$ task for six animals was sorted by left or right sample lever trials and calculated across daily sessions of 100 trials. Each symbol represents the mean performance of a single $D M S$ session; error bars indicate the largest SEM for each curve. Preferred lever represents either left or right lever sample trials sorted on an individual animal basis, to indicate the trial type with a higher percent correct during the session. Nonpreferred (Non) trials were those performed on the opposite sample lever within the same session. Animals were trained to criterion $(>85 \%$ correct on trials with $\leq 5 \mathrm{sec}$ delays) for $11 \mathrm{~d}$ (Prelesion) and then received ibotenate lesions (dashed vertical line labeled $L$ ). After postoperative recovery (Postlesion), animals were trained for $5 \mathrm{~d}$ in the $D M S$ task with $0 \mathrm{sec}$ delays and then for $11 \mathrm{~d}$ at $0-30 \mathrm{sec}$ delays. To test postoperative recovery further (2nd Postlesion), a second set of 0 sec trial delay ( $5 \mathrm{~d}$ ) and then $0-30 \mathrm{sec}$ trial delay $(24 \mathrm{~d})$ sessions were conducted (dotted vertical line at $R$ ). Preferred and nonpreferred trial types were determined independently within each daily session. $B, D M S$ performance over the same sessions shown in $A$ was sorted into groups of trials with delays of 1-10, 11-20, or 21-30 sec. Each symbol represents the mean number of trials within each group over each daily session. Trials were not sorted according to preference. For $0 \mathrm{sec}$ trial delay sessions (unfilled squares), all trials are shown. Pre- and postlesion sessions, means, and SEMs are as described in $A$.
Figure 6, top left, shows the prelesion behavioral performance of all HIPP-lesioned animals in both the DMS and DNMS tasks, segregated into the above four combinations of preferred and nonpreferred trial sequences. As reported previously for intact animals (Deadwyler et al., 1996; Hampson and Deadwyler, 1996b), the major factor influencing performance was whether the previous trial was the same $(\mathrm{P}-\mathrm{P}, \mathrm{N}-\mathrm{N})$ as, or different $(\mathrm{P}-\mathrm{N}$, $\mathrm{N}-\mathrm{P}$ ) from, the current trial. The proactive influence of same versus different trials was not present on trials occurring within 25 sec (including ITI of $10 \mathrm{sec}$ ) of the previous trial. The divergence in performance on same versus different trials in intact animals as trials became separated by $>25 \mathrm{sec}$ (Fig. 6, top right) is not a primacy or recency effect (Bolhuis and Van Kampen, 1988; Gaffan and Gaffan, 1992). Rather, the separation results from a shift in response strategy that only occurs after errors on longdelay trials (i.e., a long-delay error or LDE; Deadwyler et al., 1996). Sequential trial analyses showed that animals can minimize the likelihood of a "repeat error" after an LDE if they respond as if the opposite trial type (to the LDE) is going to occur on the next trial. This maximizing strategy produces the same/different segregation (Fig. 6, top right) and results in a reduced likelihood of a second error, especially if the next trial encountered has a long delay (Hampson and Deadwyler, 1996b). After implementing the strategy, intact animals perform the next trial in the task in accordance with the DMS/DNMS contingency. This maximization strategy is the only sequential dependency that has been identified in intact animals in this version of the DMS/DNMS task (Hampson et al., 1998a,b), and it was clearly exhibited in prelesion performance by all animals that subsequently received either type of lesion.

\section{Postlesion influences}

After ibotenate lesions that successfully removed only the hippocampus in pretrained (HIPP-lesioned) animals, proactive influences were assessed based on the above trial preferences and sequential influences. A major effect of the lesion in both the DMS and DNMS tasks related to a shift in the dominance of preferred $(\mathrm{P})$ versus nonpreferred $(\mathrm{N})$ previous trial influence (instead of same or different) on the next trial (Fig. 6, middle). Performance in pretrained HIPP-lesioned animals was not homogenous with respect to similarity of trial type. For instance, when a preferred trial followed a preferred trial, performance was 
A. Trial Type DNMS

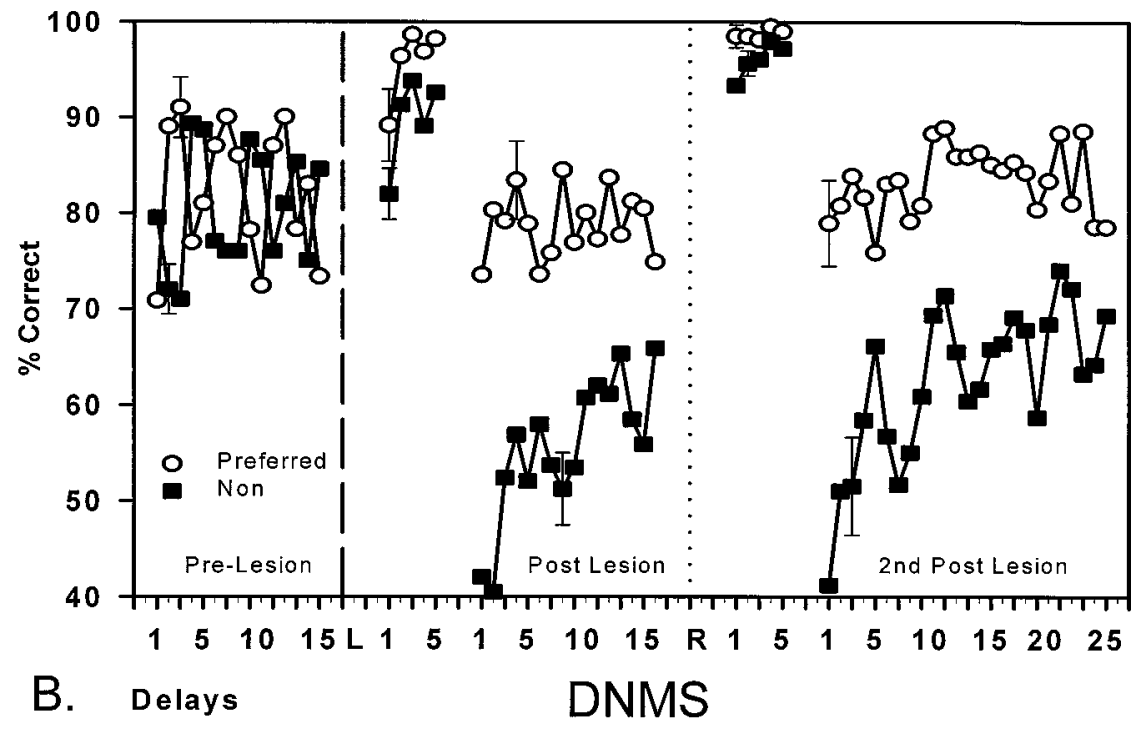

Figure 5. DNMS performance in HIPP-lesioned animals. $A$, Mean performance in the $D N M S$ task for six animals sorted by left or right sample lever trials and calculated across daily sessions on 100 trials. Plots of differential trial performance were constructed and preferred and nonpreferred trial types determined independently within each set of 0 or $0-30 \mathrm{sec}$ delay sessions from the percent correct of each trial type as described in Figure 4A. Animals were trained to criterion in the DNMS task at 0-30 sec delays before lesions (Prelesion) and then for $5 \mathrm{~d}$ at 0 delay after lesions (Postlesion). An initial set of $16 \mathrm{~d}$ at $0-30 \mathrm{sec}$ trial delays and then a second set of 0 sec delay $(5 \mathrm{~d})$ and $0-30 \mathrm{sec}$ trial delay sessions (24 d) (2nd Postlesion) were conducted (dashed line at $R$ ). Each point represents the mean overall performance on a daily $D N M S$ session, with the largest SEM within each curve indicated by the error bars as described in Figure $4 A$. B, DNMS performance over the same sessions shown in $A$ sorted into groups of trials with delay lengths of $1-10,11-20$, or $21-30 \mathrm{sec}$. Trials were sorted as described in Figure $4 B$. Pre- and postlesion sessions, means, and SEMs are as described in $A$.

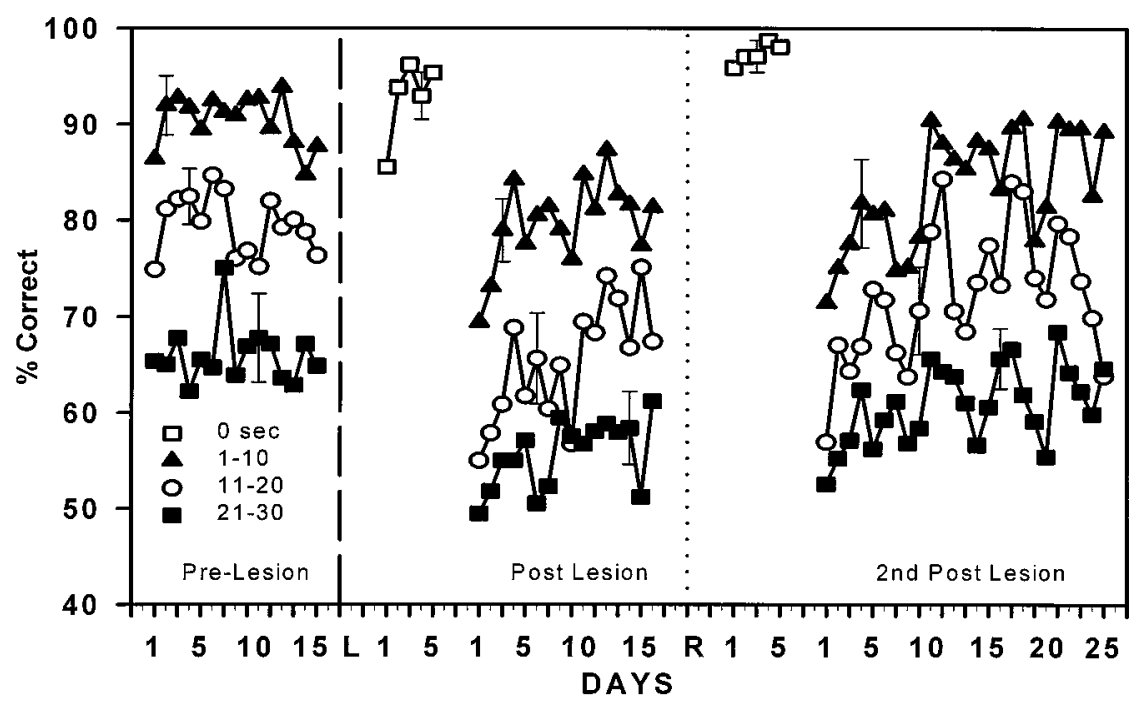

maximized at all delay intervals (Fig. 6, middle left, Pref-Pref). Inspection of the data revealed that this occurred most often when short-delay $\mathrm{P}$ trials followed correct $\mathrm{P}$ trials of any delay length. In contrast, performance on $\mathrm{N}-\mathrm{N}$ trial sequences was never above chance if trials had $>5.0 \mathrm{sec}$ delays (Fig. 6, middle left, Non-Non), irrespective of how far in time the two trials were separated (Fig. 6, middle right, Non-Non). Thus, performance was segregated along a completely different behavioral dimension than before the lesion.

An overall probability of $73 \%$ correct on any given trial was the result of a differential distribution of $78 \%$ correct on preferred trials and $68 \%$ correct on nonpreferred trials. In circumstances in which the current trial differed from the previous trial (i.e., $\mathrm{P}-\mathrm{N}$ or $\mathrm{N}-\mathrm{P}$ sequences), performance in pretrained HIPP-lesioned animals was strictly a decreasing function of length of the delay on the current trial (Fig. 6, middle left, Pref-Non). This resulted from a tendency to shift responding to the $\mathrm{P}$ type (see below) if the delay exceeded $15 \mathrm{sec}$. The most influential trial sequence in pretrained HIPP-lesioned animals was the $\mathrm{P}-\mathrm{N}-\mathrm{P}$ sequence. In particular, when a correct preferred trial with delay of $<15 \mathrm{sec}$ preceded a nonpreferred trial $(\mathrm{P}-\mathrm{N}$ sequence) with delay of $<5$ sec, the nonpreferred trial was correct $>80 \%$ of the time. Surprisingly, however, when a preferred trial with delay of $>5 \mathrm{sec}$ followed a correct nonpreferred trial (N-P sequence), the P trial was likely to be incorrect ( $80-85 \%$ errors) as shown in Figure 6, middle right. The latter anomaly is not easily explained (see Discussion); however it does illustrate a profound change in sequential trial influence in pretrained HIPP-lesioned animals after the surgery.

\section{Lack of previous training on DMS/DNMS and HIPP lesions}

Previous training also proved to be a powerful factor that interacted with the effect of HIPP lesions. Two animals trained after the lesion on the DNMS task had reliable HIPP lesions. These two naive HIPP-lesioned animals exhibited an overall performance level of $79 \%$ (Fig. 6 , bottom), significantly above $\left[F_{(10,1263)}\right.$ $=2.63 ; p<0.001]$ pretrained HIPP lesioned animals but significantly lower $\left[F_{(10,1263)}=2.80 ; p<0.001\right]$ than the prelesion performance of that same group (Fig. 6, top). However, like pretrained HIPP animals, naive HIPP animals exhibited performance that was differentially influenced $\left[F_{(10,1263)}=2.51 ; p<\right.$ 

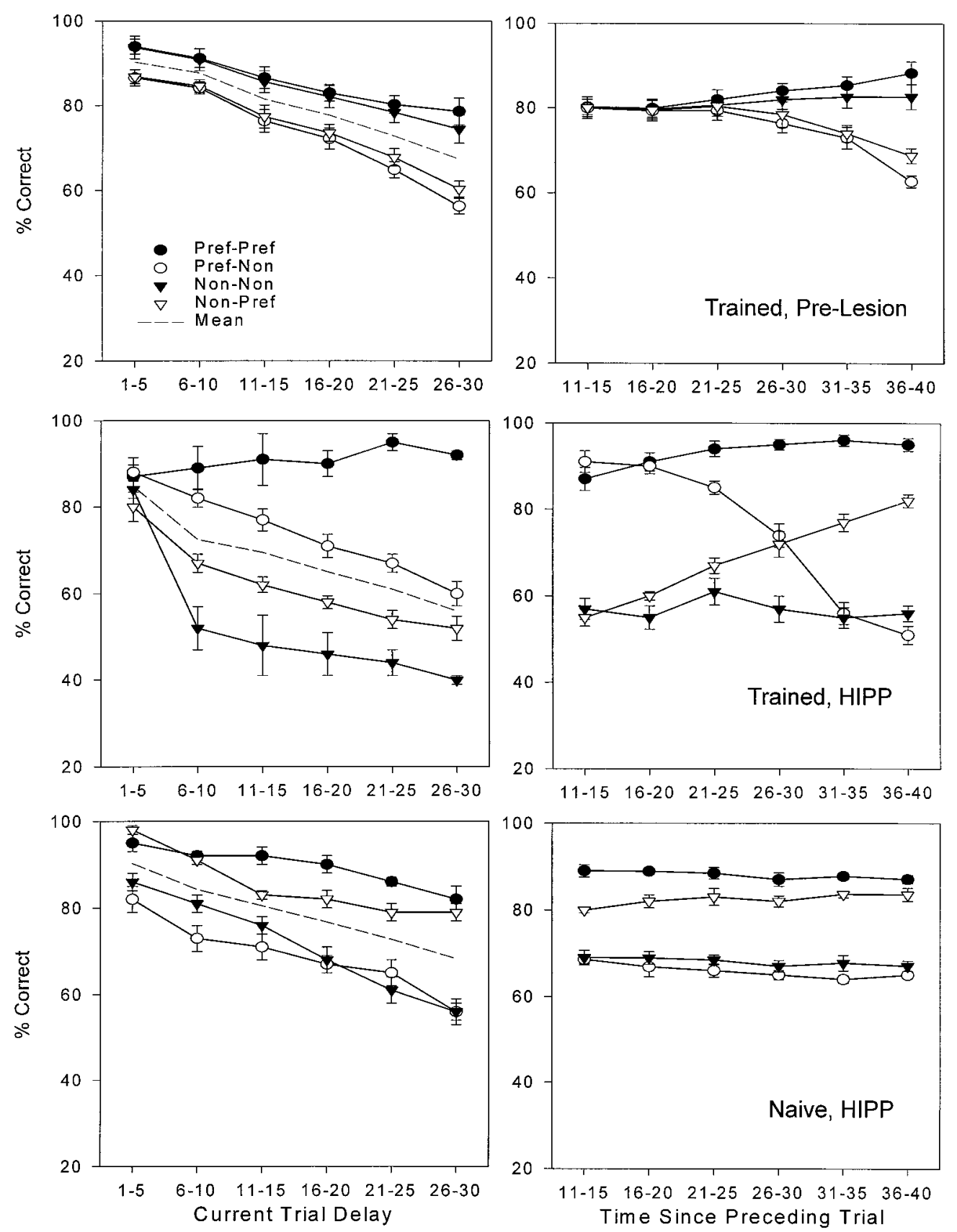

Figure 6. Comparison of preferred and nonpreferred trial influence in pretrained HIPP-lesioned animals. Top left, DMS and DNMS trial performance in 12 trained, nonlesioned animals ( 11 sessions) sorted according to the delay interval of each trial in 5 sec increments as described in Figure 3 . Data were additionally sorted by sample lever position in the current and preceding trial. After trials were sorted according to sample lever position, the set of trials with higher mean performance was termed the preferred lever type (Pref), and the set with lower performance the nonpreferred lever type (Non). Trials were additionally sorted according to whether the preceding trial was the same (i.e., Pref-Pref and Non-Non, filled symbols) or different (Pref-Non and Non-Pref, unfilled symbols). The mean ( \pm SEM) within each delay and trial type is plotted. Note that P-P and N-N trials had were higher in performance than $\mathrm{P}-\mathrm{N}$ and $\mathrm{N}-\mathrm{P}$ trial sequences, but there was no difference as a function of $\mathrm{P}$ versus $\mathrm{N}$ trials. The dashed line indicates the mean performance over all trials. Top right, DMS and DNMS trial performance in the same trained, nonlesioned animals analyzed on the left sorted according to Pref and Non trial type on the current and preceding trial and graphed as a function of time since the preceding trial (ITI of 10 sec). Delays were sorted into $5 \mathrm{sec}$ increments to match the range of delays on the previous trial. The separation in performance for same versus different trials after long delays indicates the influence of proactive interference on the trial after a long-delay error. Middle left, Postlesion DMS and DNMS trial performance in the same 12 animals (11 sessions) with HIPP lesions. Trials were sorted according to Pref versus Non trial types as described above. Note that postlesion trial performance was influenced by lever preference as well as by proactive influences. Middle right, Performance for HIPP-lesioned animals over the same trials shown at left, except sorted by time since the preceding trial. Note the influence of lever preference on $\mathrm{P}-\mathrm{P}$ and $\mathrm{N}-\mathrm{N}$ trial sequence with no change in performance across delay, compared with the reversal shown by $\mathrm{P}-\mathrm{N}$ and N-P trials (see text). Bottom, DNMS trial performance in two animals (16 sessions) with HIPP lesions that were not trained (Naive) before the lesion. Trials were sorted as described above with the current trial delay on the left and the time since the last trial on the right. Note in both panels that the influence of lever preference was greater than its associated proactive effect on the next trial (see text). 
0.01] by preferred versus nonpreferred trials (Fig. 6, bottom left). Performance in naive HIPP-lesioned animals, however, was superior on nonpreferred trials to that of pretrained HIPP-lesioned animals, especially at longer $(>6.0 \mathrm{sec}$ ) delay intervals (Fig. 6, bottom left). The parallel sets of flat curves in Figure 6, bottom right, indicate another difference with respect to training status; the proactive effect of time between trials did not interact statistically $\left[F_{(10,1263)}=4.39 ; p<0.001\right]$ with $\mathrm{P}$ and $\mathrm{N}$ trials in naive HIPP-lesioned animals (Fig. 6, bottom).

\section{Effects of hippocampal removal with collateral retrohippocampal damage}

Animals with HCX lesions sustained destruction of tissue in surrounding retrohippocampal areas (subiculum, pre- and parasubiculum, and entorhinal cortex) in addition to complete removal of the hippocampus (see Fig. 2, $H C X$ ). Three groups of animals sustaining such damage were examined: (1) pretrained HCX-lesioned animals $(n=4)$, (2) partially trained (see Materials and Methods) HCX-lesioned animals $(n=4)$, and (3) naive HCX-lesioned animals $(n=4)$ that received no training before the lesion. Animals in all HCX lesion groups were trained on the DMS or DNMS version of the task. HCX-lesioned animals were given the same number of training days that pretrained HIPPand HCX-lesioned animals received before surgery. After the lesion, naive and partially trained HCX-lesioned animals were trained to $90 \%$ correct performance on $0 \mathrm{sec}$ delay trials. There were no differences in performance between any of the HCXlesioned animals $\left[F_{(8,451)}=0.47, \mathrm{NS}\right]$ before initiation of testing with $0-30$ sec delays.

\section{Pretrained HCX-lesioned animals}

The number of days to achieve criterion performance of the HCX-lesioned animals before surgery was not significantly different $\left[F_{(10,1263)}=0.49, \mathrm{NS}\right]$ from the prelesion performance of HIPP animals with respect to either task (DMS vs DNMS). Although overall postlesion performance in pretrained HCXlesioned animals was highly impaired (69\% correct) relative to prelesion performance levels $\left[F_{(10,1263)}=4.32 ; p<0.001\right.$; Fig. 7 top, dotted line], overall performance was not significantly different compared with the postlesion performance of pretrained HIPP-lesioned animals $\left[71 \% ; F_{(10,1263)}=0.83\right.$, NS]. However, three major differences between pretrained HIPP- and HCXlesioned animals were detected; (1) performance was more dichotomized with respect to preferred (mean $=81 \%$ correct) versus nonpreferred $($ mean $=48 \%)$ trials $\left[F_{(10,1263)}=8.17 ; p<\right.$ 0.001 ; Fig. 7 , top left $]$, (2) performance on $\mathrm{P}-\mathrm{N}$ trial sequences was not differential with respect to delay (Fig. 7, top left), and (3) proactive influences were strongly dictated by temporal proximity to the previous trial $\left[F_{(10,1263)}=5.21 ; p<0.001\right]$. The HCX lesion uncovered a strong "recency effect" that rapidly dissipated after $15 \mathrm{sec}$ in lieu of the overriding P/N trial bias (HIPP-lesioned animals; Fig. 7, top right).

\section{Partially trained HCX-lesioned animals}

Figure 7, middle left and middle right, shows performance by HCX-lesioned animals trained to lever press before the lesion (partially trained). As with pretrained HCX-lesioned animals, performance on preferred trials was significantly $\left[F_{(10,1263)}=\right.$ 4.91; $p<0.001]$ elevated relative to that on nonpreferred trials across all delays; however, the degree of separation between preferred versus nonpreferred trials was significantly reduced in comparison $\left[F_{(10,1263)}=5.73 ; p<0.001\right]$. Partially trained HCX- lesioned animals showed significantly lower overall performance $\left[F_{(10,1263)}=3.84 ; p<0.001\right]$ than did naive HCX-lesioned animals, especially on nonpreferred trials at all delays (Fig. 7, middle, bottom $)$. Most importantly, the same recency effect $\left[F_{(4,1263)}=\right.$ 4.19; $p<0.001]$ seen in pretrained HCX-lesioned animals was also evident in partially trained HCX-lesioned animals (Fig. 7, middle right).

\section{Naive HCX-lesioned animals}

Naive HCX-lesioned animals $(n=4)$ showed the least impairment of DMS and DNMS performance of all HCX-lesioned animals (Fig. 7, bottom). This group exhibited superior overall performance, compared with both pretrained (69\%) and partially trained HCX-lesioned animals $\left[73 \% ; F_{(10,1263)}>2.63 ; p<0.001\right]$. Naive HCX-lesioned animals took fewer days to reach the criterion performance of $85 \%$ correct for trials with $\leq 5 \mathrm{sec}$ delays $($ mean $=16.4 \mathrm{~d})$ than did pretrained $($ mean $=21.6 \mathrm{~d})$ or partially trained $($ mean $=22.3 \mathrm{~d}$ ) HCX-lesioned animals. However, consistent with all lesion effects, trials with delays of $>6 \mathrm{sec}$ showed performance segregated into preferred versus nonpreferred categories $\left[F_{(10,1263)}=3.19 ; p<0.001\right]$, but to a much lesser degree than in other HCX-lesioned animals (Fig. 7, bottom left). Naive HCX-lesioned animals also showed the same recency effect related to temporal proximity of the previous trial $\left[F_{(10,1263)}=1.91\right.$; $p<0.05$ ] that pretrained HCX animals showed, although, again, this was significantly reduced.

\section{Lesion versus training effects in DMS and DNMS performance}

It is clear from the above results that two major variables, (1) type of lesion and (2) presence of previous training, affected the performance of all lesioned animals. Figure 8 summarizes the effects of these two variables for each of the four major lesion groups plotted as a function of delay interval. The curves with solid versus unfilled symbols (Fig. 8) reflect differences in pretrained versus naive lesioned animals in each lesion condition (HIPP vs HCX). The bold (dashed vs solid) lines depict differences in performance between $\mathrm{HCX}$ - and HIPP-lesioned animals.

With respect to performance, there was a marked delaydependent two-way interaction $\left[F_{(9,1261)}=13.67 ; p<0.001\right]$ between both the type of lesion and whether the animals were pretrained on the task. At delays of $>10 \mathrm{sec}$, performance of both naive lesion groups (HIPP and HCX) was superior to that of pretrained lesioned animals with the same type of lesion. Also, HCX-lesioned animals irrespective of pretraining showed significantly worse performance at delays of $\leq 10 \mathrm{sec}$ than did HIPPlesioned animals $\left[F_{(1,1261)}=6.43 ; p<0.01\right]$. Thus pretraining on the task had no influence on performance at short ( $\leq 10 \mathrm{sec})$ delay intervals, but HCX-lesioned animals showed significantly more impairment than did HIPP-lesioned animals at these delays.

At longer delays $(>15 \mathrm{sec})$, pretraining interacted significantly with the severity of the lesion deficit $\left[F_{(9,1261)}=4.22 ; p<0.001\right]$. The most striking example was the performance of naive HCXlesioned animals (Fig. 8, dashed line with unfilled inverted triangles) that was impaired on trials with short delays $(0-10 \mathrm{sec})$ but not significantly different from the performance of intact animals on trials at the longest delays $(26-30 \mathrm{sec})$. In contrast, the performance of pretrained HIPP-lesioned animals (Fig. 8, solid line with filled squares) exhibited no effect on performance at $0 \mathrm{sec}$ delays but a classic delay-dependent decrease (relative to prelesion levels) for all other delays. Finally, pretrained HCX-lesioned 

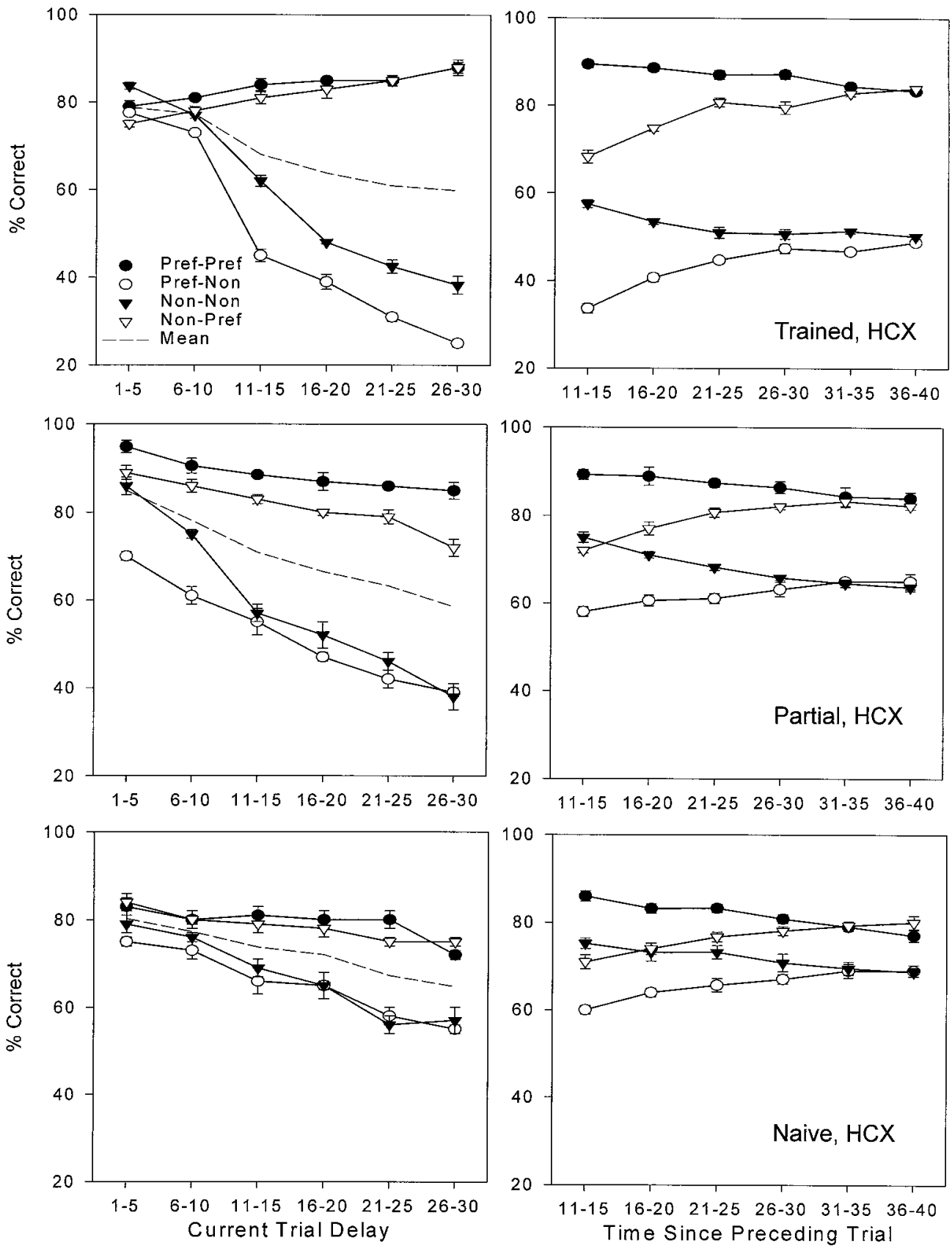

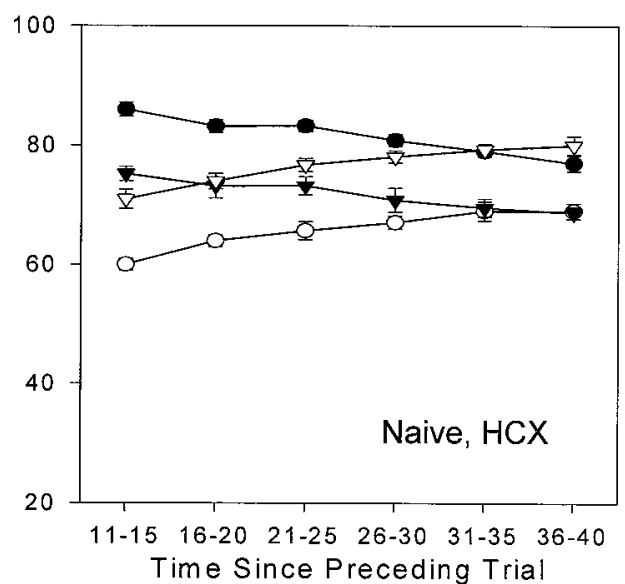

Figure 7. Comparison of preferred and nonpreferred trial influence in pretrained $H C X$-lesioned animals. Performance sorted by preferred (Pref) versus nonpreferred (Non) trial type for pairs of trials (preceding and current) as shown in Figure 6. Data are shown for three groups: animals that were fully pretrained before the lesion (Top; Trained, $H C X ; n=4$ animals, 10 sessions), animals that were partially trained before the lesion (Middle; Partial, $H C X ; n=4$ animals, 11 sessions), and animals that were not trained before the lesion (Bottom; Naive, HCX; $n=4$ animals, 16 sessions). Mean ( \pm SEM) DMS and DNMS performance sorted according to current trial delay is shown on the left; performance sorted according to time since the preceding trial is shown on the right Dashed lines (left) indicate mean performance across all trials for a given training group. Symbols are described in Figure 6. animals exhibited even greater performance deficits at intermediate delays $(6-17 \mathrm{sec})$ than did both naive HCX-lesioned and pretrained HIPP-lesioned animals (Fig. 8). This dissociation between extent of lesion and previous training as a function of delay interval provides very strong evidence of differential processing of information by hippocampal versus retrohippocampal structures as a function of previous experience with the task (Hampson et al., 1995).

\section{Changes in proactive influences in lesioned animals}

Several factors led to differences in the performance of lesioned versus intact animals. A concise description of these differences with respect to one of the most influential variables, previous trial sequence, is presented in this section. In most cases these differences were severely exaggerated in animals trained before the lesion (Figs. 6-8). To assess changes in such proactive influences, a measure of the degree of influence of previous trial sequences on a given trial was derived by sorting trials by all possible combinations of three trials (the relevant or current trial being the last trial in the three trial sequence). Each third trial in the sequence was analyzed on the basis of whether there was a significant deviation from mean overall performance as a function of the preceding of two trials. The proportion of third trials in which no significant change from overall performance occurred was determined and considered to be controlled primarily by "within"-trial influences, whereas those in which the previous sequence affected performance were considered to be controlled by "between"-trial influences. Both between- and within-trial influences were further identified in terms of the length of delay. Only trials in which the two above influences could be clearly isolated (i.e., $>15 \%$ difference in performance of the third trial as 


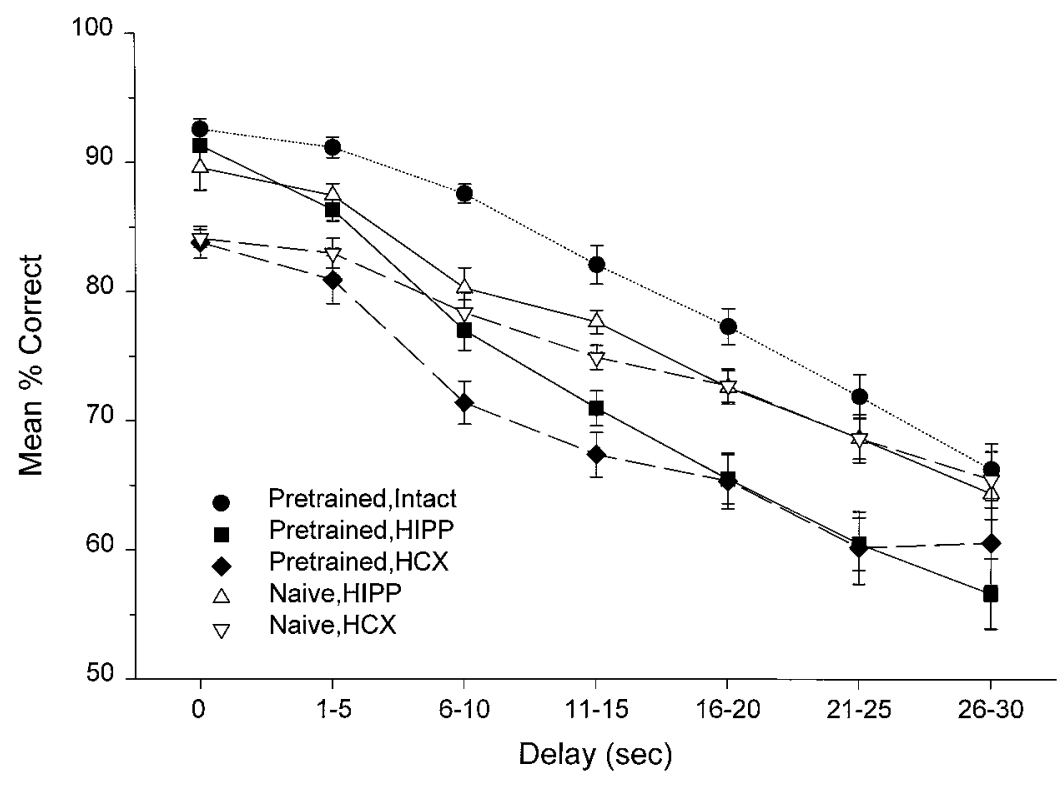

Figure 8. DMS and DNMS performance curves for all combinations of task training and type of lesion. Combined mean ( \pm SEM) DMS and DNMS performance across all trials. Performance is shown for animals trained before $H I P P$ (Pretrained, HIPP) or $H C X$ (Pretrained, $H C X$ ) lesion as well as for animals that were not trained (i.e., Naive) before receiving $H I P P$ or $H C X$ lesion. Performance in the combined intact group before lesion (Pretrained, Intact) is shown for comparison. Filled versus unfilled symbols indicate the trained versus untrained groups, respectively. Solid versus dashed lines indicate $H I P P$ versus $H C X$ lesions, respectively.

a function of the previous sequence) were included in the analysis ( $\sim 50 \%$ of total trials), because the other trial sequences consisted of runs of like trials and single alternating sequences, both of which contained strong preference effects (Figs. 4-7). The same types of trial sequences were compared in all four groups of animals, generating between- and within-trial performance curves for (1) intact animals, (2) pretrained HIPP-lesioned animals, (3) pretrained HCX-lesioned animals, and (4) naive HIPPand HCX-lesioned animals (combined).

Figure 9, $A-C$, shows performance curves for within- and between-trial influences as a function of the delay for all four groups. For intact animals, on trials in which there was minimal previous trial influence, increasing the trial delay produced only a slight decrease in mean performance (Fig. 9A, Control Within). The same measure plotted after both types of lesions revealed a striking deficit in performance $\left[F_{(10,388)} \geq 3.58 ; p<0.001\right]$ on trials with $>5$ sec delays (Fig. $9 B, C, H I P P, H C X)$. The dotted line in Figure $9 A$ indicates that both the within- and between-trial influences on performance in the combined naive HIPP- and HCX-lesioned animals were markedly reduced $\left[F_{(10,388)}=2.55\right.$; $p<0.01]$ relative to pretrained lesioned animals. The difference between the intact group performance (Fig. 9B, C, replotted as dotted line) and the lesion group curves across increasing delays is a measure of the inability to sustain use of within-trial information to solve the task.

The complementary plot for trials in which the previous sequence significantly affected DMS and DNMS performance is shown as unfilled symbols in Figure $9, A-C$. Figure $9 A$ shows that in intact animals, between-trial influences are minimal on trials of $<10$ sec delay and increase linearly to maximum on trials with the longest delays (30 sec) where within- and between-trial performance curves are maximally separated. This indicates that a major detrimental influence on performance in intact animals is previous trial sequence when delays exceed 10-15 sec. This appeared to be the case in pretrained HIPP-lesioned animals as well, even though overall performance was significantly decreased $\left[F_{(10,388)}=2.39 ; p<0.01\right]$ at all delays (Fig. 9B). Performance was significantly decreased at all delays $>5 \mathrm{sec}$ relative to overall mean levels $\left[F_{(10,388)}=5.31 ; p<0.001\right]$ and with respect to the performance of intact animals $\left[F_{(10,388)}=6.47 ; p<0.001\right]$ under the same sequential influences. It is clear that proactive influences increased as delay increased for intact and pretrained HIPP-lesioned animals (Fig. 9A,B) but leveled off quickly at delays of $>15 \mathrm{sec}$ for pretrained HCX-lesioned animals (Fig. 9C). Thus, pretrained HCX-lesioned animals showed a more severe impairment from previous trial influences (with little delay dependence) than did pretrained HIPP-lesioned animals $\left[F_{(10,388)}\right.$ $=4.22 ; p<0.001]$. The inset in Figure $9 C$ shows that one reason for the severe deficit in pretrained HCX-lesioned animals (triangles) was the previously described strong recency effects (Fig. 7) resulting from this lesion, illustrated here as a significant difference $\left[F_{(10,388)}=5.16 ; p<0.001\right]$ in the percent change in performance on trials in which recency effects were most likely to occur (i.e., preceding trials that were closer in time).

\section{DISCUSSION}

The findings described here indicate that the hippocampus plays a key role in the performance of tasks in which retention of item-specific information across variable delay intervals is required. In each instance in which animals were tested before and after the lesion, performance in both tasks (i.e., DMS and DNMS) was equally impaired relative to prelesion levels (Fig. 3). A major finding in the present study was that animals with complete and selective removal of the hippocampus (HIPP lesion) were severely compromised in terms of retention of itemspecific information within a trial and also highly susceptible to trial biases (preferences) as well as sequential dependencies between trials (Figs. 6, 9). Hippocampal removal that also caused collateral damage to adjacent structures (HCX-lesioned animals) produced added deficits in the form of strong recency effects (Figs. 7, 9). Performance in all pretrained (HIPP or HCX) lesioned animals never recovered to prelesion levels over $\sim 40$ successive days of postoperative training (Figs. 4, 5). Quite unexpected was the finding that animals trained after either type of lesion (naive-lesioned animals) showed less impairment on the tasks than did pretrained lesioned animals, suggesting that pretraining with the hippocampus intact rendered remaining anatomic structures (retrohippocampal) less capable of adapting to perform the task (see below).

The most distinct consequence of isolated and complete hip- 
A.

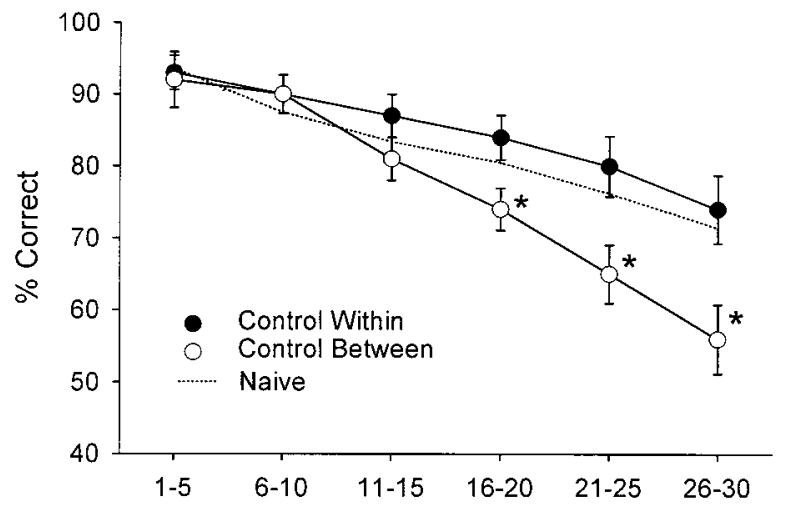

C.

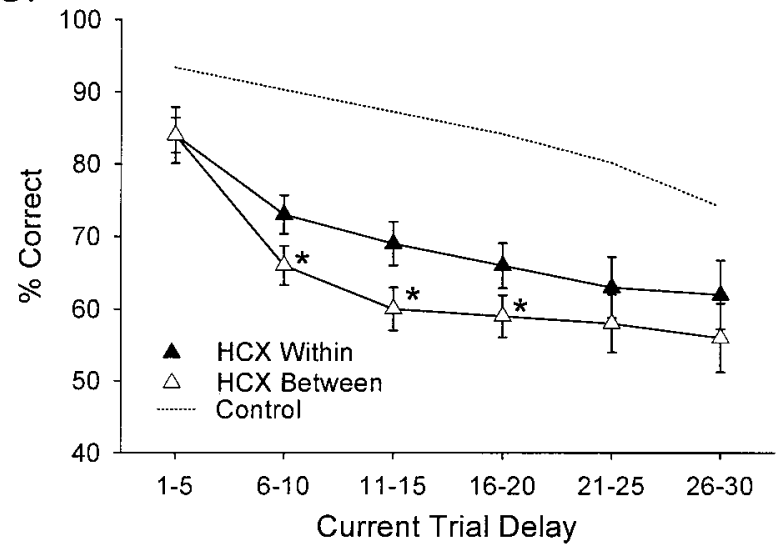

B.

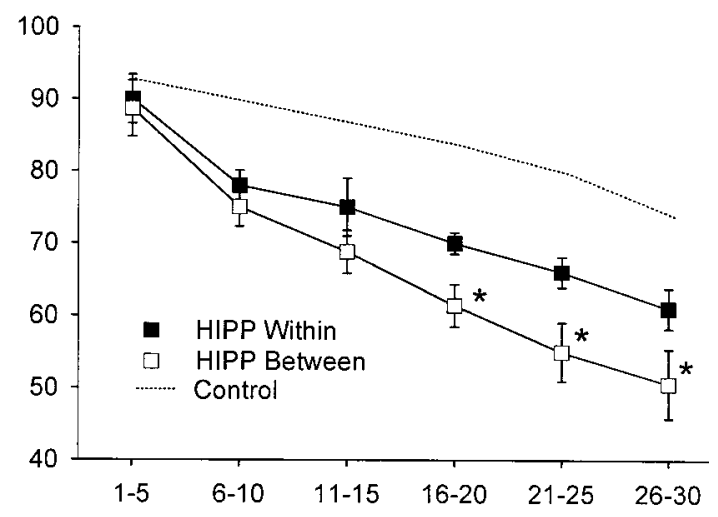

D.

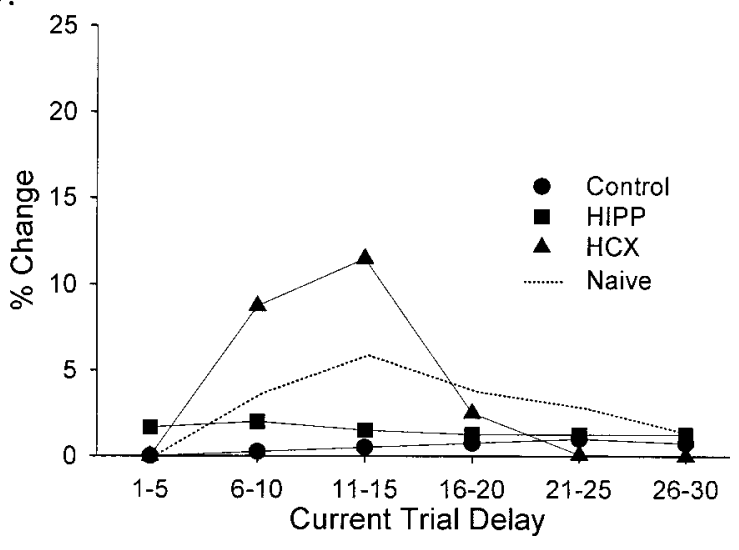

Figure 9. Separation of within- versus between-trial influences for intact and pretrained HIPP- and HCX-lesioned animals. Trials were sorted as a function of three trial sequences and categorized with respect to significant influences of the previous two trials on the performance of the third trial in the sequence. The trials were then averaged and plotted as a function of delay interval of that third trial. This provided an estimate of the degree to which animals could perform the trial based only on DMS and DNMS contingencies operating within the trial independent of between-trial (i.e., proactive) influences. Between- and within-trial performance curves were calculated only from sequences in which the previous trial was of a different type ( $\sim 50 \%$ of total trials). A, Intact animals. Within-trial performance curve ( filled circles) for intact (Control Within) animals is plotted as mean percent correct $( \pm$ SEM) across all delays for trials in which there was no between-trial influence. Between-trial performance curve for intact animals (unfilled circles) shows a sharp decline for $>10 \mathrm{sec}$ delay trials, indicating increased proactive influence as the delay on the current trial is increased. The dotted curve indicates the performance of the combined naive (HIPP and HCX) lesioned animals. Significance levels for all points [pairwise comparisons, within vs between, $\left.F_{(1.388)}>10.9\right]$ are indicated at $p<0.001$ (asterisks). B. Pretrained HIPP-lesioned animals. Within- and between-trial performance curves for pretrained HIPP-lesioned animals are shown. The dotted curve represents the within-trial curve for intact animals (Control) in $A$ replotted for comparison. $C$, Pretrained HCX-lesioned animals. Within- and between-trial performance curves for pretrained HCX-lesioned animals are shown. The dotted curve is a replot of the intact animal (Control) within-trial curve as in $B$. D. Small graph (Recency) showing the effects of recency removed from all other between-trial sequential influences for each of the four groups of animals (Control, circles; HIPP, squares; HCX, triangles; and combined Naive, dashed line). The only trial sequences plotted were those that produced recency effects in pretrained (triangles) or naive (dashed line) HCX-lesioned animals.

pocampal removal was the fixation of a permanent preference for a particular trial type (Figs. 4, 6). This tendency interacted with other proactive factors that affected performance at all delays (Figs. 4, 6, 9). Before the lesion, such preferences were not consistent over sessions and did not influence performance (Fig. 6, top). After surgery in pretrained HIPP- and HCX-lesioned animals, this bias maximized performance $(>90 \%)$ on preferred trials and reduced responding to chance levels on all but the shortest-delay nonpreferred trials (Figs. 6, 7). Numerous other studies of hippocampal lesions on spatial and nonspatial tasks in rats have identified factors affected by the lesion, including stimulus complexity (Rawlins et al., 1993; Yee and Rawlins, 1994; Cassaday and Rawlins, 1995), context (Davidson and Jarrard, 1993; Honey and Good, 1993; Deacon and Rawlins, 1995), response strategies (Rawlins et al., 1988; Gutnikov et al., 1994;
Gutnikov and Rawlins, 1996), and amount of information per trial (Steele and Rawlins, 1993), as well as the effects of reinforcement per se (Jarrard et al., 1986; Yee et al., 1997). However, few have mentioned the type of trial-based preference identified in the pretrained HIPP- and HCX-lesioned rats described here. Dunnett (1989) described a deficit in fornix-lesioned animals that exacerbated the same/different differentiation seen in normal animals (Fig. 6, top), but this was not analyzed in terms of preferred versus nonpreferred trial differences.

One possible explanation is that animals with hippocampal ibotenate lesions respond faster than intact animals (Jarrard, 1993) such that on operant-type tasks like the one used here, failure to inhibit responding at the appropriate time may influence performance. Although such disinhibition could contribute to the deficit, a complete analysis must take into account the fact 
that performance was decreased in both the DMS and DNMS types of tasks, which eliminates explanations in terms of a simple response bias for one or the other levers. At long-delay intervals, lesioned animals essentially performed only one trial type; therefore, it seems that they were impaired when required to perform in the opposite manner (i.e., nonpreferred trials) with respect to sample and to match or nonmatch task requirements using the same stimuli.

The above results are somewhat inconsistent with reports of the lack of severity of either electrolytic or excitotoxic lesions of the hippocampus on DMS and/or DNMS performance in rodents (Lyford et al., 1993; Rawlins et al., 1993; Steele and Rawlins, 1993; Jarrard and Davidson, 1994; Yee and Rawlins, 1994). Those studies indicated that unless areas other than the hippocampus were affected the performance deficit was relatively small. It is not known whether the marked deficit demonstrated in HIPPlesioned animals in this version of the DNMS and DMS task was caused by the differential spatial requirements of task-relevant responses (Jarrard, 1995) or other factors such as exaggerated proactive interference from the previous trial (Deacon and Rawlins, 1995). It has been suggested that motor mediation may account for successful DMS and DNMS performance in rats tested in other types of rodent DMS and DNMS tasks (Gutnikov et al., 1994; Chudasama and Muir, 1997). Although this possibility was to a large extent eliminated by the apparatus design and version of the current tasks (Fig. 1), such a behaviorally dependent explanation could still not account for the sequence- and time-dependent nature of the effects of prior trials in lesioned animals (Fig. 9) or for the marked differentiation of performance on preferred versus nonpreferred trials (Figs. 4-7) in the present study.

A second important finding derived from post hoc analyses of the data was that the pretrained (HIPP and HCX) lesioned animals were not performing the delay tasks in the same manner as before the lesion, or with the same success as animals trained after the lesion (Figs. 6-8). Pretrained HIPP-lesioned animals seemed to revert to alternation strategies in which runs of the same type of trials could be performed at maximum levels $(93 \%$ correct) if the trials were of the preferred (P) type (Fig. 6, middle). Nonpreferred (N) trials were performed at random unless they closely followed a short successful preferred trial. It is possible that all animals have an innate response bias in the task that is normally masked and of little influence on performance because of effective memory for the sample information across most delays. The inability to suppress response bias in lesioned animals may therefore be an indirect outcome of the memory impairment in the task, even though it seems to reflect a maximization strategy. Pretrained HCX-lesioned animals showed a pronounced recency effect in addition to these same $\mathrm{P}$ and $\mathrm{N}$ biases (Fig. 7, top). Animals trained after the lesion exhibited delay-dependent performance levels significantly above those of pretrained HIPP- and HCX-lesioned animals, suggesting that they were less susceptible to $\mathrm{P}$ and $\mathrm{N}$ trial differences.

Another difference between the two types of lesions in pretrained animals seemed to be the ability to perform the tasks at long-delay intervals. When delay curves exhibit parallel shifts at all delays, Ringo (1991) has maintained that memory disruption is not delay dependent. Demonstration of selective hippocampal involvement in the task requires under this assumption that performance at the very shortest delay intervals $(1.0 \mathrm{sec})$ be maintained, whereas performance at longer delays is systematically more impaired (Figs. 3, 8, 9). The corresponding difference in slope of the pre- versus post-HIPP and -HCX lesion withintrial curves (Fig. 9A) indicates that the deficit can in part be attributed to an inability to perform at delays of $>6 \mathrm{sec}$ when other between-trial factors are accounted for. A similar delay specificity was shown to be responsible for performance deficits in studies with nonhuman primates (Alvarez-Royo et al., 1992).

The results of the present study also suggest that the long-held notion of well learned tasks being less affected by hippocampal lesions (cf. Squire, 1992) might have to be modified for tasks that use highly redundant trial-specific information. In the reported studies with hippocampal ibotenate lesions, very few animals are tested on the same task before and after the lesion to compare differences in performance as a function of when the lesion was administered (Irle and Markowitsch, 1990; Ridley et al., 1996). The present results indicate that certain retrohippocampal areas may have been permanently "altered" during prelesion training on the task, such that after hippocampal removal, the remaining postlesion plasticity was insufficient to allow these areas to be modified to perform the task to the same level as animals that were not pretrained (Figs. 8, 9). Thus, performance that required the use of within-trial information was severely disrupted in pretrained lesioned animals but spared to a large extent in naive lesioned animals trained after surgery (Fig. 9A, dotted curve). It is also clear from Figures 4 and 5 that postlesion performance did not improve significantly in pretrained HIPP-lesioned animals even though extensive retraining sessions were provided.

In the emerging conceptualization of the role of medial temporal lobe structures in memory (Eichenbaum, 1997), the hippocampus has been relegated the specific function of supporting semantic (Squire and Zola, 1997; Reed and Squire, 1998) versus episodic (Tulving and Markowitsch, 1997; Vargha-Khadem et al., 1997) memory processes. Substantial evidence now shows the importance of other temporal lobe structures, in particular perirhinal and postrhinal cortex as well as retrohippocampal regions (subiculum, parasubiculum, and entorhinal cortex), in traditional "hippocampal-type" memory deficits (Suzuki et al., 1993; Zola-Morgan et al., 1993; Squire and Zola, 1997). This has been supported by recent studies showing independent anatomic connectivity between the above retrohippocampal and cortical areas and their associated input structures (Burwell et al., 1995; Tamamaki and Nojyo, 1995; McIntyre et al., 1996; Naber et al., 1997; Burwell and Amaral, 1998; Naber and Witter, 1998).

In the present study, differentiation between the involvement of the hippocampus in DMS and DNMS performance and retrohippocampal areas in rodents confirms the distinction in roles played by these different areas. The emergence of a strong recency effect not present in HIPP-lesioned animals (Figs. 8, 9B) was a shared characteristic of all HCX-lesioned animals, irrespective of when the animals were trained relative to surgery. It is interesting that in the present study, variable combinations of collateral damage to retrohippocampal structures (subiculum, pre- and/or parasubiculum, and entorhinal cortex) across different animals led to similar deficits in all HCX-lesioned animals (Fig. 7). This raises the interesting possibility that damage to any of these retrohippocampal areas interrupted a "functional circuit" (Eichenbaum et al., 1994; Eichenbaum, 1997; Murray and Mishkin, 1998) through which information could be processed either in conjunction with (pretrained HCX-lesioned animals) or parallel to (naive HCX-lesioned animals) the hippocampus. Lesions of the entorhinal and perirhinal cortex that spare hippocampus in the rat also produce major deficits in delay-type tasks (Rothblat et al., 1993; Holscher and Schmidt, 1994; Glasier et al., 1995; Wiig and 
Burwell, 1998). Therefore it is possible that if the animal is pretrained with all structures (i.e., circuits) intact, areas that remain after the removal of the hippocampus lose the ability to adjust the processing of task-relevant information to compensate for hippocampal removal.

Vargha-Khadem et al. (1997) showed the surprising dissociation of amnesia from other types of intellectual abilities in children suffering damage to the hippocampus as infants, suggesting that the semantic memory system may be able to overcome hippocampal insult but that episodic memory remains impaired. The finding has provoked serious re-evaluation of whether hippocampal damage affects only episodic or also semantic memory in humans (Squire and Zola, 1997; Tulving and Markowitsch, 1997). Eichenbaum (1997) suggests that similar data are available from animal studies in that hippocampal-lesioned rats: (1) "lack flexibility in adapting appropriate strategies based on nonexplicitly paired stimulus elements and (2) are highly susceptible to interference from similar types of stimulus elements." The above findings in this study in which hippocampal removal impaired permanently the use of within-trial information in pretrained HIPP- and HCX-lesioned animals provides evidence of a distinction in the two processes. These deficits were either not present or severely reduced in naive lesioned animals, demonstrating the flexibility of intact retrohippocampal areas to overcome the loss of hippocampal structures as long as critical processes within those regions have not been altered, as in "hippocampaldependent learning" before the lesion.

A recent report by Murray and Mishkin (1998) showed that selective ibotenate removal of hippocampus and amygdala did not produce deficits in DNMS tasks in nonhuman primates. Using tasks in which such deficits had been demonstrated in the past, the authors suggest that other lesion methods used in monkeys interrupted fibers projecting from subiculum to and from perirhinal and entorhinal cortex and other structures (Stefanacci et al., 1996). Although this contradicts some earlier reports of the necessity of hippocampal involvement in DNMS performance (Zola-Morgan et al., 1982, 1989a; Murray and Mishkin, 1984; Zola-Morgan and Squire, 1990; Alvarez-Royo et al., 1995), it is consistent with a series of recent studies showing more pronounced effects of perirhinal, postrhinal, and parahippocampal lesions on delay tasks in nonhuman primates (Zola-Morgan et al., 1989b,c; Gaffan and Murray, 1992; Meunier et al., 1993; Suzuki et al., 1993; Leonard et al., 1995).

There are some caveats to the Murray and Mishkin (1998) study however. The first has to do with the lack of an effect of delay on memory in the task that was not disrupted by their lesions. Control animals in their study did not exhibit memory deficits at any delay (except when list length and delay were combined), rendering the absence of a lesion effect somewhat questionable. Secondly, there were acknowledged differences in the type of pretraining received by the animals that were compared in that study (Zola-Morgan et al., 1989b,c; Meunier et al., 1993). In view of the findings reported here with rodents, it is possible that the lack of a deficit may have interacted with the extent of training before the lesion. Third, with respect to the stated necessity to interrupt the projection from retrohippocampal areas to entorhinal or postrhinal cortex (Stefanacci et al., 1996), the present findings reveal marked deficits in delaydependent performance without such encroachment, when fibers of passage remained intact (Fig. 2) (Jarrard, 1989, 1991). In addition, when such collateral damage did occur, some deficits were qualitatively different than removal of hippocampus alone (i.e., HIPP vs HCX). Finally, in none of the animals in the HIPP-lesioned group was damage to the amygdala or surrounding structures noted. Thus it is unlikely that the deficit attributed to HIPP-lesioned animals in the current study was the result of the interruption of the pathway claimed by Murray and Mishkin (1998) to be relevant for short-term memory in monkeys.

One reason isolated hippocampal removal was so devastating in this study may have been the heavy "spatial loading" inherent in the operant task used. It is evident from the rodent literature that the hallmark indicator of hippocampal damage is performance deficits in tasks requiring use of spatial information (Morris et al., 1982; Morris, 1991). Because the performance of HIPP- and HCX-lesioned animal at delays of $<6.0 \mathrm{sec}$ was unaffected (Figs. $6-9)$, it could be hypothesized that (1) spatial information is inherently more difficult to encode than nonspatial information (Hampson and Deadwyler, 1996a; Deadwyler and Hampson, 1997), (2) spatial information is more susceptible to the types of proactive interference inherent on each trial as the delay increases (Fig. 9B), or (3) after spatial information is encoded, it "decays" at a higher rate across the delay than nonspatial information (Fig. 9A). Whatever the reason, it is clear that animals with complete and isolated hippocampal removal did not perform the task in the same manner as before the lesion. The deficit was a direct function of the same variable that makes the task difficult to perform in intact animals, i.e., the increasing temporal interval between the encoding of the sample information and the subsequent retrieval of that information to make a specific discriminative response. In that context, the results support and confirm extensive electrophysiological studies showing a close correspondence between the "strength" or "distinctiveness" of the neural code for the sample stimulus indicated by the intensity of cell firing within ensembles of hippocampal neurons and the ability to perform the task at extended delay intervals (Deadwyler et al., 1996; Deadwyler and Hampson, 1997; Hampson et al., 1998b). Therefore, unless the hippocampus is present to provide or regulate such encoding, the accuracy of performance in delay tasks will depend on when the hippocampus is removed during training as well as on the extent to which remaining retrohippocampal areas can subsume that encoding function (Fig. 8).

\section{REFERENCES}

Aggleton JP, Mishkin M (1985) Mammillary-body lesions and visual recognition in monkeys. Exp Brain Res 58:190-197.

Aggleton JP, Blindt HS, Rawlins JNP (1989) Effects of amygdaloid and amygdaloid-hippocampal lesions on object recognition and spatial working memory in rats. Behav Neurosci 103:962-974.

Alvarez-Royo P, Zola-Morgan S, Squire LR (1992) Impairment of longterm memory and sparing of short-term memory in monkeys with medial temporal lobe lesions: a response to Ringo. Behav Brain Res $53: 1-5$.

Alvarez-Royo P, Zola-Morgan S, Squire LR (1995) Damage limited to the hippocampal region produces long-lasting memory impairment in monkeys. J Neurosci 15:3796-3807.

Angeli SJ, Murray EA, Mishkin M (1993) Hippocampectomized monkeys can remember one place but not two. Neuropsychologia 31:1021-1030.

Bolhuis JJ, Van Kampen HS (1988) Serial position curves in spatial memory of rats: primacy and recency effects. Q J Exp Psychol 40B:135-149.

Burwell RD, Amaral DG (1998) Perirhinal and postrhinal cortices of the rat: interconnectivity and connections with entorhinal cortex. J Comp Neurol 391:293-321.

Burwell RD, Witter M, Amaral DG (1995) The perirhinal and postrhinal cortices of the rat: a review of neuroanatomical literature and comparison with findings in the monkey brain. Hippocampus 5:390-408. 
Cassaday HJ, Rawlins JN (1995) Fornix-fimbria section and working memory deficits in rats: stimulus complexity and stimulus size. Behav Neurosci 109:594-606.

Chudasama Y, Muir Jl (1997) A behavioral analysis of delayed nonmatching to position task: the effects of scopolamine, lesions of the fornix and the prelimbic region in mediating behaviors by rats. Psychopharmacology (Berl) 134:73-82.

Coffey PJ, Perry VH, Rawlins JN (1990) An investigation into the early stages of the inflammatory response following ibotenic acid-induced neuronal degeneration. Neuroscience 35:121-132.

Correll RE, Scoville WB (1965) Performance on delayed match following lesions of medial temporal lobe structures. J Comp Physiol Psychol 60:360-367.

Davidson TL, Jarrard LE (1993) The hippocampus and metabolic state cues. Behav Neural Biol 59:107-111.

Deacon RMJ, Rawlins JNP (1995) Serial position effects and duration of memory for nonspatial stimuli in rats. J Exp Psychol Gen 21:285-292.

Deadwyler SA, Hampson RE (1997) The significance of neural ensemble codes during behavior and cognition. In: Annual review of neuroscience, Vol 20 (Cowan W M, Shooter EM, Stevens CF, Thompson RF, eds), pp 217-244. Palo Alto, CA: Annual Reviews.

Deadwyler SA, Bunn T, Hampson RE (1996) Hippocampal ensemble activity during spatial delayed-nonmatch-to-sample performance in rats. J Neurosci 16:354-372.

Dunnett SB (1989) Comparison of short-term memory deficits in animal models of aging using an operant delayed response task in rats. In: The biology of memory (Squire LR, Lindenlaub E, eds), pp 581-603. New York: Schattauer Verlag.

Eichenbaum H (1997) How does the brain organize memories? Science 277:330-332.

Eichenbaum H, Otto T, Cohen NJ (1994) Two functional components of the hippocampal memory system. Behav Brain Sci 17:449-518.

Fink RP, Heimer L (1967) Two methods for selective silver impregnation of degenerating axons and their synaptic endings in the CNS. Brain Res 4:269-274.

Gaffan D, Murray EA (1992) Monkeys (Macaca fascicularis) with rhinal cortex ablations succeed in object discrimination learning despite 24-hr inertial intervals and fail at matching to sample despite double sample presentations. Behav Neurosci 106:30-38.

Gaffan EA, Gaffan D (1992) Less-than-expected variability in evidence for primacy and von Restorff effects in rats non-spatial memory. J Exp Psychol Gen 18:298-301.

Glasier MM, Sutton RL, Stein DG (1995) Effects of unilateral entorhinal cortex lesion and ganglioside GM1 treatment on performance in a novel water maze. Neurobiol Learning Memory 64:203-214.

Gutnikov SA, Rawlins JNP (1996) Systemic NMDA antagonist CGP37849 produces non-specific impairment in a working memory task: the effect does not resemble those of AP5 and of lesions of the hippocampus or fornix. Neuropsychologia 34:311-314.

Gutnikov SA, Barnes JC, Rawlins JN (1994) Working memory tasks in five-choice operant chambers: use of relative and absolute spatial memories. Behav Neurosci 108:899-910.

Hampson RE, Deadwyler SA (1996a) LTP and LTD and the encoding of memory in small ensembles of hippocampal neurons. In: Long-term potentiation, Vol 3 (Baudry M, Davis J, eds), pp 199-214. Cambridge, MA: MIT.

Hampson RE, Deadwyler SA (1996b) Ensemble codes involving hippocampal neurons are at risk during delayed performance tests. Proc Natl Acad Sci USA 93:13487-13493.

Hampson RE, Heyser CJ, Deadwyler SA (1993) Hippocampal cell firing correlates of delayed-match-to-sample performance in the rat. Behav Neurosci 107:715-739.

Hampson RE, Byrd DR, Konstantopoulos JK, Bunn T, Deadwyler SA (1995) Proactive interference and short-term memory during performance of a DNMS task in normal rats and rats with hippocampus removed. Soc Neurosci Abstr 21:1215.

Hampson RE, Rogers G, Lynch G, Deadwyler SA (1998a) Facilitative effects of the ampakine CX516 on short-term memory in rats: enhancement of delayed-nonmatch-to-sample performance. $\mathrm{J}$ Neurosci 18:2740-2747.

Hampson RE, Rogers G, Lynch G, Deadwyler SA (1998b) Facilitative effects of the ampakine CX516 on short-term memory in rats: correlations with hippocampal neuronal activity. J Neurosci 18:2748-2763.

Holscher C, Schmidt WJ (1994) Quinolinic acid lesion of the rat entorhinal cortex pars medialis produces selective amnesia in allocentric working memory (WM) but not in egocentric WM. Behav Brain Res 63:187-194.

Honey RC, Good M (1993) Selective hippocampal lesions and behavior: effects of kainic acid lesions on performance of place and cue tasks. Behav Neurosci 107:23-33.

Irle E, Markowitsch HJ (1990) Functional recovery after limbic lesions in monkeys. Brain Res Bull 25:79-92.

Jarrard LE (1989) On the use of ibotenic acid to lesion selectively different components of the hippocampal formation. J Neurosci Methods 29:251-259.

Jarrard LE (1991) Use of ibotenic acid to selectively lesion brain structures. In: Methods in neurosciences, Vol 7, pp 58-69. New York: Academic.

Jarrard LE (1993) On the role of the hippocampus in learning and memory in the rat. Behav Neural Biol 60:9-26.

Jarrard LE (1995) What does the hippocampus really do? Behav Brain Res 71:1-10.

Jarrard LE, Davidson TL (1994) The hippocampus and complex, nonspatial discrimination: is learning still "not possible"? In: Neurobehavioral plasticity: learning, development and response to brain insults (Spear NE, Spear LP, Woodruff M, eds).

Jarrard LE, Feldon J, Rawlins JNP, Sinden JD, Gray JA (1986) The effects of intrahippocampal ibotenate on resistance to extinction after continuous or partial reinforcement. Exp Brain Res 61:519-530.

Leonard BW, Amaral DG, Squire LR, Zola-Morgan S (1995) Transient memory impairment in monkeys with bilateral lesions of the entorhinal cortex. J Neurosci 15:5637-5659.

Lyford GL, Gutnikov SA, Clark AM, Rawlins JN (1993) Determinants of non-spatial working memory deficits in rats given intraventricular infusions of the NMDA antagonist AP5. Neuropsychologia 31:1079-1098.

Maren S, Aharonov G, Fanselow MS (1997) Neurotoxic lesions of the dorsal hippocampus and Pavlovian fear conditioning in rats. Behav Brain Res 88:261-274.

McIntyre DC, Kelly ME, Staines WA (1996) Efferent projections of the anterior perirhinal cortex of the rat. J Comp Neurol 369:302-318.

Meunier M, Bachevalier J, Mishkin M, Murray EA (1993) Effects of visual recognition of combined and separate ablations of the entorhinal and perirhinal cortex in rhesus monkeys. J Neurosci 13:5418-5432.

Morris RGM (1991) Distinctive computations and relevant associative processes: hippocampal role in processing, retrieval, but not storage of allocentric spatial memory. Hippocampus 1:287-290.

Morris RGM, Garrud P, Rawlins JNP, O'Keefe J (1982) Place navigation impaired in rats with hippocampal lesions. Nature 297:681-683.

Murray EA, Mishkin M (1984) Severe tactual as well as visual memory deficits follow combined removal of the amygdala and hippocampus in monkeys. J Neurosci 4:2565-2580.

Murray EA, Mishkin M (1998) Object recognition and location memory in moneys with excitotoxic lesions of the amygdala and hippocampus. J Neurosci 18:6568-6582.

Naber PA, Witter M (1998) Subicular efferents are organized mostly as parallel projections: a double-labeling, retrograde-tracing study in the rat. J Comp Neurol 393:284-297.

Naber PA, Caballero-Bleda M, Jorritsma-Byham B, Witter M (1997) Parallel input to the hippocampal memory system through peri- and postrhinal cortices. NeuroReport 8:2617-2621.

Olton DS, Feustle WA (1981) Hippocampal function required for nonspatial working memory. Exp Brain Res 41:380-389.

Parkinson JK, Murray EA, Mishkin M (1988) A selective mnemonic role for hippocampus in monkeys: memory for the location of objects. J Neurosci 8:4159-4167.

Raffaele KC, Olton DS (1988) Hippocampal and amygdaloid involvement in working memory for nonspatial stimuli. Behav Neurosci 102:349-355.

Rawlins JNP (1985) Associations across time: the hippocampus as a temporary memory store. Behav Brain Sci 8:479-528.

Rawlins JNP, Maxwell TJ, Sinden JD (1988) The effect of fornix section on win-stay/lose-shift and win-shift/lose-stay performance in the rat. Behav Brain Res 31:17-28.

Rawlins JNP, Lyford GL, Seferiades A, Deacon RM, Cassaday HJ (1993) Critical determinants of nonspatial working memory deficits in rats with conventional lesions of the hippocampus or fornix. Behav Neurosci 107:420-433.

Reed JM, Squire LR (1998) Retrograde amnesia for facts and events: findings from four new cases. J Neurosci 18:3943-3954. 
Ridley RM, Baker HF, Harder JA, Person C (1996) Effects of lesions of different parts of the septo-hippocampal system in primates on learning and retention of information acquired before or after surgery. Brain Res Bull 40:21-32.

Ringo JL (1991) Memory decays at the same rate in macaques with and without brain lesions when expressed in d' or arcsine terms. Behav Brain Res 42:123-134.

Rothblat LA, Kromer LF (1991) Object recognition memory in the rat: the role of the hippocampus. Behav Brain Res 42:25-32.

Rothblat LA, Vnek N, Gleason TC, Kromet LF (1993) Role of parahippocampal region in spatial and non-spatial memory: effects of parahippocampal lesions on rewarded alternation and concurrent object discrimination learning. Behav Brain Res 55:93-100.

Shaw C, Aggleton JP (1995) Evidence for the independence of recognition and recency memory in amnesic subjects. Cortex 31:57-71.

Squire LR (1992) Memory and the hippocampus: a synthesis from findings with rats, monkeys, and humans. Psychol Rev 99:195-231.

Squire LR, Zola SM (1997) Episodic memory, semantic memory and amnesia. Hippocampus 8:205-211.

Steele K, Rawlins JNP (1993) The effects of hippocampectomy on performance by rats of a running recognition task using long lists of non-spatial items. Behav Brain Res 54:1-10.

Stefanacci L, Suzuki WA, Amaral DG (1996) Organization of connections between the amygdala complex and the perirhinal and parahippocampal cortices in macaque monkeys. J Comp Neurol 375:552-582.

Suzuki WA, Zola-Morgan S, Squire LR, Amaral DG (1993) Lesions of the perirhinal and parahippocampal cortices in the monkey produce long-lasting memory impairment in the visual and tactual modalities. J Neurosci 13:2430-2451.

Tamamaki N, Nojyo Y (1995) Preservation of topography in the connections between the subiculum, field CA1 and the entorhinal cortex in rats. J Comp Neurol 353:379-390.

Tulving E, Markowitsch HJ (1997) Episodic and declarative memory: role of hippocampus. Hippocampus 8:198-204.
Vargha-Khadem F, Gadian DG, Watkins KE, Connelly A, Van Paesschen W, Mishkin M (1997) Differential effects of early hippocampal pathology on episodic and semantic memory. Science 277: 376-380.

Wiig K, Burwell RD (1998) Memory impairment on a delayed nonmatching-to-position task after lesions of the perirhinal cortex in the rat. Behav Neurosci 112:827-838.

Yee BK, Rawlins JN (1994) The effects of hippocampal formation ablation or fimbria-fornix section on performance of a nonspatial radial arm maze task by rats. J Neurosci 14:3766-3774.

Yee BK, Feldon J, Rawlins JNP (1997) Cytotoxic lesions of the retrohippocampal region attenuate latent inhibition but spare the partial reinforcement extinction effect. Exp Brain Res 115:247-256.

Zola-Morgan S, Squire LR (1990) Identification of the memory system damaged in medial temporal lobe amnesia. In: The biology of memory (Squire LR, Lindelaub E, eds), pp 509-521. Stuttgart: Schattauer.

Zola-Morgan S, Squire LR, Mishkin M (1982) The neuroanatomy of amnesia: amygdala-hippocampus versus temporal stem. Science 218:1337-1339.

Zola-Morgan S, Squire LR, Amaral DG (1989a) Lesions of the hippocampal formation but not lesions of the fornix or the mammillary nuclei produce long-lasting memory impairment in the monkey. J Neurosci 9:897-912.

Zola-Morgan S, Squire LR, Amaral DG (1989b) Lesions of the amygdala that spare adjacent cortical regions do not impair memory or exacerbate the impairment following lesions of the hippocampal formation. J Neurosci 9:1922-1936.

Zola-Morgan S, Squire LR, Amaral DG, Suzuki WA (1989c) Lesions of the perirhinal and parahippocampal cortex that spare the amygdala and hippocampal formation produce severe memory impairment. J Neurosci 9:4355-4370.

Zola-Morgan S, Squire LR, Clower RP, Rempel NL (1993) Damage to the perirhinal cortex exacerbates memory impairment following lesions to the hippocampal formation. J Neurosci 13:251-265. 